\begin{tabular}{|c|c|}
\hline Title & $\begin{array}{l}\text { Three dimensional resistivity structure of A sama V olcano reveal ed by data space magnetotelluric inversion using } \\
\text { unstructured tetrahedral elements }\end{array}$ \\
\hline Author(s) & $\begin{array}{l}\text { Usui, Y oshiya; Ogawa, Y asuo; A izawa, Koki; Kanda, W ataru; Hashimoto, Takeshi; Koyama, Takao; Y amaya, Y usuke; } \\
\text { Kagiyama, T suneomi }\end{array}$ \\
\hline Citation & $\begin{array}{l}\text { Geophysical Journal International, 208(3), 1359-1372 } \\
\text { https://doi.org/10.1093/gji/ggw } 459\end{array}$ \\
\hline Issue Date & 2017-03 \\
\hline Doc URL & http:/hdl. handle.net/2115/67559 \\
\hline Rights & $\begin{array}{l}\text { This article has been accepted for publication in Geophysical Journal International @: } 2017 \text { The A uthors. Published by } \\
\text { Oxford University Press on behalf of the Roy al A stronomical Society. All rights reserved. }\end{array}$ \\
\hline Type & article \\
\hline File Information & Geophys. J. Int.208-3_1359-1372.pdf \\
\hline
\end{tabular}

Instructions for use 


\title{
Three-dimensional resistivity structure of Asama Volcano revealed by data-space magnetotelluric inversion using unstructured tetrahedral elements
}

\author{
Yoshiya Usui, ${ }^{1,2}$ Yasuo Ogawa, ${ }^{1,2}$ Koki Aizawa, ${ }^{3}$ Wataru Kanda,,${ }^{1,2}$ Takeshi Hashimoto, ${ }^{4}$ \\ Takao Koyama, ${ }^{5}$ Yusuke Yamaya ${ }^{6}$ and Tsuneomi Kagiyama ${ }^{7}$ \\ ${ }^{1}$ Department of Earth and Planetary Sciences, Tokyo Institute of Technology, Tokyo 152-8550, Japan. E-mail: usui.y.ad@m.titech.ac.jp \\ ${ }^{2}$ Volcanic Fluid Research Center, Tokyo Institute of Technology, Tokyo 152-8550, Japan \\ ${ }^{3}$ Institute of Seismology and Volcanology, Faculty of Sciences, Kyushu University, Nagasaki 855-0843, Japan \\ ${ }^{4}$ Institute of Seismology and Volcanology, Faculty of Science, Hokkaido University, Hokkaido 060-0810, Japan \\ ${ }^{5}$ Volcano Research Center, Earthquake Research Institute, University of Tokyo, Tokyo 113-0032, Japan \\ ${ }^{6}$ Fukushima Renewable Energy Institute, National Institute of Advanced Industrial Science and Technology, Fukushima 963-0298, Japan \\ ${ }^{7}$ Aso Volcanological Laboratory, Institute for Geothermal Sciences, Graduate School of Science, Kyoto University, Kumamoto 869-1233, Japan
}

Accepted 2016 December 1. Received 2016 November 30; in original form 2016 July 24

\begin{abstract}
SUMMAR Y
Asama Volcano is an andesitic composite volcano and one of the most active volcanoes in Japan. In order to reveal electrical resistivity structure beneath the volcano accurately, we performed a 3-D inversion of dense magnetotelluric survey data. In order to prevent misinterpretation of the subsurface resistivity due to the steep topography around Asama Volcano, we used an unstructured tetrahedral mesh to represent the topography. Furthermore, we reduced the calculation time by transforming the inverse problem from the model space into the data space. Comparison of the new data-space method to the original model-space method showed that the calculation time required to update the model parameters was reduced as a result of the transformation, whereas the resistivity structure obtained remained unchanged. In the subsurface resistivity structure around Asama Volcano that was estimated from the inversion, resistive bodies were discovered to be located under the old eruption centres. In particular, under the $24 \mathrm{ka}$ collapse caldera to the west of the presently active crater, a spherical resistive body was found to exist in isolation. In addition, there was a widespread conductive layer below the resistive surface layer. By comparison with previous hydrological and geochemical studies, the conductive layer was interpreted as being a high-water-content layer and an overlying layer rich in altered clay minerals. Because the western part of the volcanic conduit was considered to be the resistive area, which is inferred to consist of unfractured rocks with lower permeability than their surroundings, it would appear that the area obstructs the westward flow of the hydrothermal fluid beneath the summit, thereby contributing to higher concentrations of $\mathrm{SO}_{4}{ }^{2-}$ and $\mathrm{Cl}^{-}$in the spring water at the northern and eastern feet as well as the uneven location of a diffuse $\mathrm{CO}_{2}$ anomaly.
\end{abstract}

Key words: Inverse theory; Electrical properties; Magnetotellurics; Volcanic arc processes.

\section{INTRODUCTION}

Asama Volcano is an andesitic composite volcano and one of the most active volcanoes in Japan. It is composed of three consecutive volcanic edifices (Kurofu Volcano, Hotoke-iwa Volcano and Maekake Volcano in chronological order) and three lava domes (Sekison-zan, Ko-Asama and Hanareyama lava domes) (Fig. 1). The highest point of Asama Volcano is $2568 \mathrm{~m}$ above sea level (ASL) and corresponds to the summit of Maekake Volcano, where the present active crater is located. Asama Volcano constitutes a series of WNW-ESE aligned volcanoes, known as the Asama-Eboshi
Volcanoes, along with the Eboshi Volcanoes located to the west. The volcanic activity of the Asama-Eboshi Volcanoes started from the westernmost part around $1 \mathrm{Ma}$, after which the active centre migrated from west to east during its history (Nishiki et al. 2013). Therefore, the topography around Asama Volcano has an east-west trend (Fig. 1). Prior to the formation of the latest edifice (Maekake Volcano), a large conical-shaped stratovolcano at 2800-2900 m ASL, Kurofu Volcano, was formed approximately $2 \mathrm{~km}$ west of the present active crater (Aramaki 1963). However, around $24 \mathrm{ka}$, the stratovolcano collapsed eastward and a horseshoe-shaped caldera remained (Nishiki et al. 2013). After the activity of Kurofu Volcano 


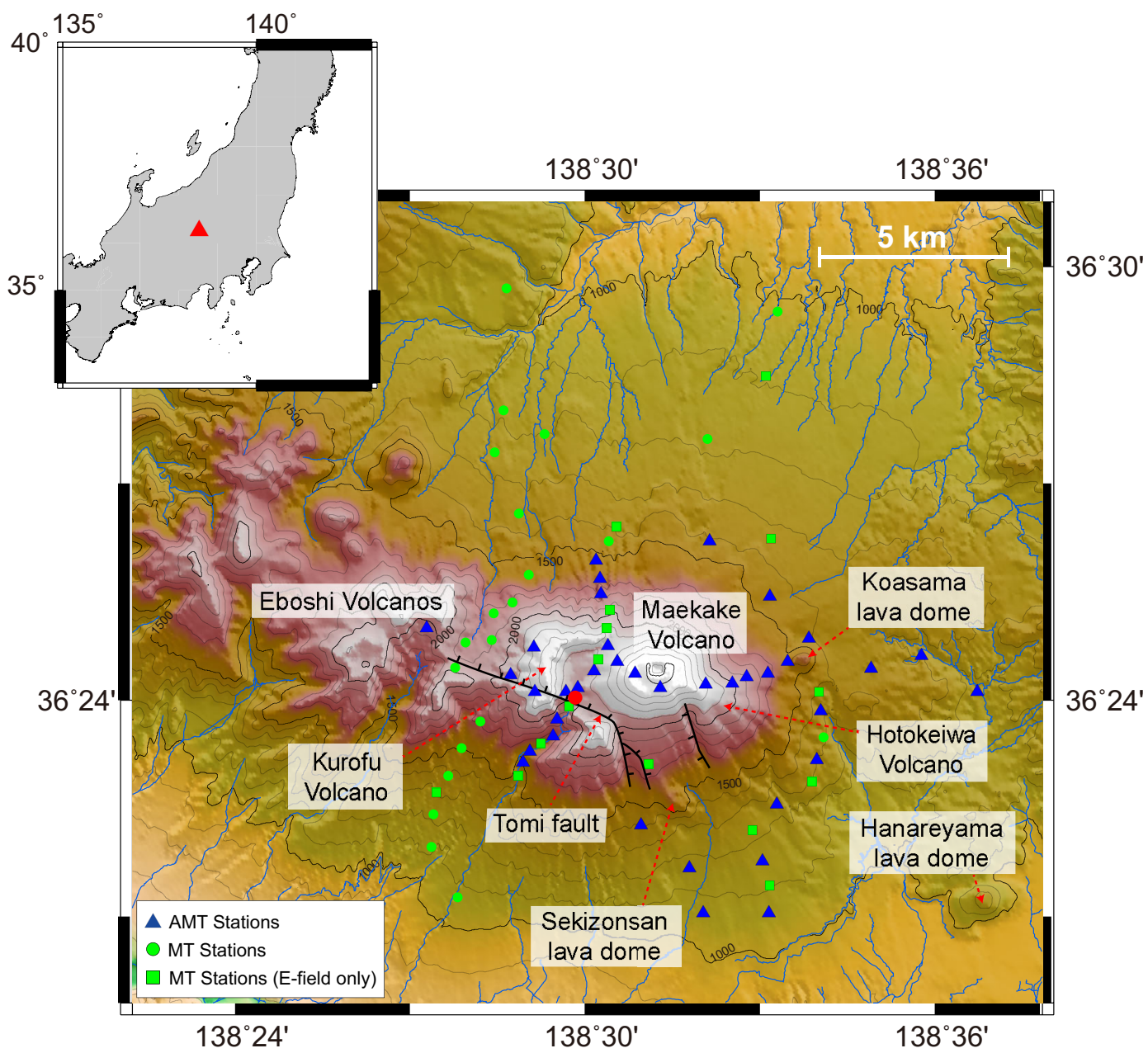

Figure 1. Spatial distribution of the magnetotelluric observation sites used in this study. Blue triangles and green circles indicate AMT and MT sites, respectively, at which both electric and magnetic fields were observed. Green squares indicate MT sites where only an electric field was observed. The altitudes and locations of rivers were extracted from the Fundamental Geospatial Data developed by GSI-Japan (Geospatial Information Authority of Japan 2011). In addition, the locations of the normal faults around the volcano (Takahashi et al. 2013) are also shown. Red filled circle indicates the location of the Jigokudani fumarolic area.

ceased, from around 17-11 ka, Hotokeiwa Volcano had been active slightly east of the present eruption crater (Nishiki et al. 2013), which was almost buried by the volcanic ejecta of the following activities of Maekake Volcano. After approximately $8.5 \mathrm{ka}$ (Nishiki et al. 2013), volcanic eruptions occurred at Maekake Volcano, which is currently active. Some normal faults are recognized in the summit area (Takahashi et al. 2013; Fig. 1), which were formed by the depression of the ground after the pumice eruptions during the last stage of the Hotokeiwa activity (Aramaki 1963).

Around Asama Volcano, continuous seismic and GPS observations have been carried out to obtain information about its subsurface structure and the mechanism of magma transportation (Aoki et al. 2013). Takeo et al. (2006) used the measurements recorded by the GPS stations to suggest the occurrence of a dyke intrusion several kilometres to the west of the summit preceding the 2004 eruption. They also revealed the sinuous hypocentre distribution under Asama Volcano and suggested that it represents the magma supply path beneath the volcano. Aoki et al. (2009) attempted to reveal the relationship between volcanic activities and the subsurface structure by conducting an active source seismic survey and found an area with high $P$-wave velocity to the west of the summit. They also showed that the high-velocity area corresponds to the high-density area inferred from Bouguer gravity anomaly. They interpreted that the area to the west of the summit contains solidified intrusive magma responsible for constraining magma migration under the volcano. On the other hand, Nagaoka et al. (2012) estimated the $S$-wave velocity structure of the upper crust around Asama Volcano by using ambient noise seismic tomography. They revealed the existence of a low-velocity area at depths of 5-10 km under the area about $8 \mathrm{~km}$ to the west of the summit. They interpreted that it represents a deep magma chamber beneath the dyke.

Preceding the seismic and geodetic studies, Aizawa et al. (2008) conducted a dense magnetotelluric (MT) survey around Asama Volcano and has already estimated the 2-D resistivity structures of three north-south profiles and one east-west profile, and they found the resistive anomalies surrounded by the conductive area. As the resistive bodies are located below the old eruption centres, the previous work suggested that the resistive anomalies are old solidified magma and that the surrounding conductive area corresponds to a hydrothermal system driven by the remaining heat of the magma. They also suggested that the old solidified magma prevents the ascent of magma. However, as the resistivity structures of the previous study were estimated from 2-D inversion, these results 
could have been subject to 3-D effects including the ones caused by steep topography around Asama Volcano.

The topography of a mountainous area can significantly influence the observational data of an MT survey (e.g. Müller \& Haak 2004; Usui 2015) such that these topographies can cause 3-D distortions to the observed data and prevent us from accurately estimating a resistivity structure from 2-D analysis. In recent years, 3-D MT inversion has become practical, and it has been applied to mountainous areas. However, in almost all the cases, the finite-difference method has been used and topographies were represented by rectangular grids. Therefore, in these calculations, mountain slopes were modelled as a sequence of steps, which resulted in incorrect discontinuities in the response functions between narrow periods unless two blocks of grid were added to each direction of the observation sites (Müller \& Haak 2004). The addition of grids to the areas around all of the sites increases the number of required grids and computational cost. Recently, Kordy et al. (2016b) developed an inversion scheme using unstructured hexahedral elements and applied it to the field data observed on Mount St. Helens Volcano. By using unstructured elements, they succeeded in representing the smooth dipping surface precisely in the computational mesh. However, when a small element was created around observation sites in a hexahedral mesh to represent precise topography, the total number of elements significantly increases since the edge lengths of the outermost area are required to be equal to those around sites.

Usui (2015) overcame these problems by developing an inversion scheme using unstructured tetrahedral elements and showed its applicability to synthetic data affected by topography. Therefore, in order to obtain accurate 3-D resistivity structure around Asama Volcano by incorporating 3-D topographic effects into the inversion model, we applied the inversion scheme of Usui (2015) to the data set of Aizawa et al. (2008). It is the first application of 3-D MT inversion using unstructured tetrahedral elements to field-observed data.

Application of the inversion scheme of Usui (2015) to an actual MT data set, however, is problematic because this approach uses the model-space Gauss-Newton method to obtain new model parameters. Recovery of a resistivity distribution with higher resolution around the observation sites requires hundreds of thousands or more parameter cells. In such cases, the model-space GaussNewton method is not practical (Kordy et al. 2016b). To overcome the problem and reduce the calculation time, we transformed the inverse problem from the model space into the data space according to Siripunvaraporn et al. (2005) and Kordy et al. (2016b).

In the following sections, a brief review of the original modelspace method of Usui (2015) is first presented, followed by a detailed description of the newly developed data-space method. Next, the observation data and calculation conditions of the inversion targeted for Asama Volcano are presented. Subsequently, the results of the inversion are described, after which the subsurface structure around Asama Volcano is inferred from the result.

\section{MODIFICATION OF INVERSION SCHEME}

\subsection{Description of the modified inversion scheme}

The 3-D inversion scheme proposed by Usui (2015) uses the modelspace Gauss-Newton method to obtain new model parameters. Assuming that these model parameters consist only of log-resistivities of parameter cells for ease of explanation, and the number of unknown log-resistivities and those of the observed data are $M_{\rho}$ and
$N$, respectively, it is necessary to solve the following linear equation at the $(k+1)$ th iteration of the method

$\left[\left(\boldsymbol{W} \boldsymbol{J}_{k}\right)^{T}\left(\boldsymbol{W} \boldsymbol{J}_{k}\right)+\alpha^{2} \boldsymbol{R}^{T} \boldsymbol{R}\right] \delta \boldsymbol{m}_{\rho, k+1}=\hat{\boldsymbol{d}}$

$\hat{\boldsymbol{d}}=-\boldsymbol{R}^{T} \boldsymbol{R} \boldsymbol{m}_{\rho, k}+\left(\boldsymbol{W} \boldsymbol{J}_{k}\right)^{T} \boldsymbol{W}\left(\boldsymbol{d}-\boldsymbol{F}\left(\boldsymbol{m}_{\rho, k}\right)\right)$,

where $\boldsymbol{W} \in \mathbb{R}^{N \times N}$ is the diagonal matrix consisting of the reciprocals of the standard deviations of observed data, $\boldsymbol{J}_{k} \in \mathbb{R}^{N \times M_{\rho}}$ is the sensitivity matrix, $\boldsymbol{R} \in \mathbb{R}^{M_{\rho} \times M_{\rho}}$ is the roughening matrix, $\delta \boldsymbol{m}_{\rho, k+1} \in \mathbb{R}^{M_{\rho}}$ consists of the increments of the model parameters at the $(k+1)$ th iteration and $\alpha \in \mathbb{R}$ is a trade-off parameter. Furthermore, $\boldsymbol{m}_{\rho, k} \in \mathbb{R}^{M_{\rho}}$ is a vector composed of the model parameters at the $k$ th iteration; $\boldsymbol{d} \in \mathbb{R}^{N}$ consists of the real and imaginary parts of observed response functions, whereas $\boldsymbol{F}\left(\boldsymbol{m}_{\rho, k}\right) \in \mathbb{R}^{N}$ consists of those of the calculated response functions. Although the solution vector is $\delta \boldsymbol{m}_{\rho, k+1}$ in eq. (1), it is equivalent to eq. (34) of Usui (2015), in which the solution vector is the model parameters at the $(k+1)$ th iteration. The roughening matrix $\boldsymbol{R} \in \mathbb{R}^{M_{\rho} \times M_{\rho}}$ gives the differences of log-resistivities of adjacent parameter cells $\boldsymbol{r}_{k} \in \mathbb{R}^{M_{\rho}}$ as

$$
\begin{aligned}
& \boldsymbol{R} \boldsymbol{m}_{\rho, k}=\boldsymbol{r}_{k}=\left(\begin{array}{lllll}
r_{k}^{1} & \cdots & r_{k}^{i} & \cdots & r_{k}^{M_{\rho}}
\end{array}\right)^{T} \\
& r_{k}^{i}=N_{F}^{i} m_{\rho, k}^{i}-\sum_{j=1}^{N_{F}^{i}} m_{\rho, k}^{j, i}
\end{aligned}
$$

where $N_{F}^{i}$ is the number of faces of the $i$ th parameter cell, $m_{\rho, k}^{i} \in \mathbb{R}$ is the log-resistivity of the $i$ th parameter cell at the $k$ th iteration and $m_{\rho, k}^{j, i} \in \mathbb{R}$ is the log-resistivity of the parameter cell adjacent to the $i$ th parameter cell through its $j$ th face. Notably, $N_{F}^{i}$ does not include the number of faces located on the outer boundary of the computational mesh, which are not shared by any adjacent cell. The coefficient matrix of eq. (1) is a dense matrix, and its dimension is $M_{\rho}$. Therefore, the more model parameters are estimated in inversion, the more CPU time is required.

To overcome the problem, we transformed the computational space from model space to data space in the same manner as Siripunvaraporn et al. (2005) and Kordy et al. (2016b). If the roughening matrix $\boldsymbol{R}$ is non-singular, it is possible to apply the Sherman-Morrison-Woodbury formula (Golub \& Van Loan 2013) to the inverse of the coefficient matrix of eq. (1) as

$$
\begin{aligned}
& \quad\left[\left(\boldsymbol{W} \boldsymbol{J}_{k}\right)^{T}\left(\boldsymbol{W} \boldsymbol{J}_{k}\right)+\alpha^{2} \boldsymbol{R}^{T} \boldsymbol{R}\right]^{-1} \\
& \quad=\left(\alpha^{2} \boldsymbol{R}^{T} \boldsymbol{R}\right)^{-1}-\left(\alpha^{2} \boldsymbol{R}^{T} \boldsymbol{R}\right)^{-1}\left(\boldsymbol{W} \boldsymbol{J}_{k}\right)^{T} \boldsymbol{\Gamma}_{k}{ }^{-1} \boldsymbol{W} \boldsymbol{J}_{k}\left(\alpha^{2} \boldsymbol{R}^{T} \boldsymbol{R}\right)^{-1} \\
& \boldsymbol{\Gamma}_{k}=\boldsymbol{I}+\left(\boldsymbol{W} \boldsymbol{J}_{k}\right)\left(\alpha^{2} \boldsymbol{R}^{T} \boldsymbol{R}\right)^{-1}\left(\boldsymbol{W} \boldsymbol{J}_{k}\right)^{T} .
\end{aligned}
$$

Although the matrix $\boldsymbol{\Gamma}_{k}$ is dense, its dimension is $N$, which represents the number of data. Therefore, even if the number of unknown log-resistivities $M_{\rho}$ is large, it does not increase the time required to calculate the inverse of $\boldsymbol{\Gamma}_{k}$. Although the rank of the roughening matrix is less than $M_{\rho}$ (Uchida 1993), the roughening matrix $\boldsymbol{R}$ is regularized by adding a small positive value $\epsilon \in \mathbb{R}$ to its diagonals as in Kordy et al. (2016b). Kordy et al. (2016b) showed that this procedure makes the roughening matrix regularized and, when $\epsilon$ is very small, its influence on the result of the inversion is negligibly small. When $\boldsymbol{R}$ is regularized in this way, from eqs (1), $(2),(5)$ and (6), the increments of the model parameters at the $(k+1)$ th iteration $\delta \boldsymbol{m}_{\rho, k+1}$ can be calculated as

$$
\begin{aligned}
\delta \boldsymbol{m}_{\rho, k+1}= & \left(\alpha^{2} \boldsymbol{R}^{T} \boldsymbol{R}\right)^{-1} \hat{\boldsymbol{d}}-\left(\alpha^{2} \boldsymbol{R}^{T} \boldsymbol{R}\right)^{-1}\left(\boldsymbol{W} \boldsymbol{J}_{k}\right)^{T} \boldsymbol{\Gamma}_{k}{ }^{-1} \\
& \times \boldsymbol{W} \boldsymbol{J}_{k}\left(\alpha^{2} \boldsymbol{R}^{T} \boldsymbol{R}\right)^{-1} \hat{\boldsymbol{d}}
\end{aligned}
$$


In our inversion code, the inverse of $\boldsymbol{\Gamma}_{k} \in \mathbb{R}^{N \times N}$ is not directly calculated; instead, it is calculated by solving the linear equation whose coefficient matrix is $\boldsymbol{\Gamma}_{k}$ with the aid of the direct solver of LAPACK (Anderson et al. 2000). As described above, the computer resources required to solve the linear equation are independent of the number of unknown log-resistivities $M_{\rho}$. Furthermore, we parallelized the construction of the coefficient matrix $\boldsymbol{\Gamma}_{k}$ by hybrid programming with MPI and OpenMP. This hybrid parallelization becomes possible by virtue of the transformation to the data space. Since, in the inversion code of Usui (2015), each of the MPI processes performs calculations of different frequencies, the construction of $\boldsymbol{\Gamma}_{k}$ can be parallelized with the multiple process as in Siripunvaraporn \& Egbert (2009) while it is difficult to parallelize the construction of the coefficient matrix of eq. (1) with MPI in an efficient way. Matrix $\left(\alpha^{2} \boldsymbol{R}^{T} \boldsymbol{R}\right)^{-1}$ is equal to the square of the inverse of $\alpha \boldsymbol{R}$ since the roughening matrix $\boldsymbol{R}$ is symmetric, and the inverse of the matrix is calculated by solving the linear equation whose coefficient matrix is $\alpha \boldsymbol{R}$. Although the dimension of the linear equation is $M_{\rho}$, it is a real sparse matrix and can be solved quickly by the MKL PARDISO library as confirmed by Kordy et al. (2016b).

When distortion matrices of observation sites are also estimated in inversion, the regularization term for them is added to the objective function as in Avdeeva et al. (2015). If the number of unknown components of distortion matrices is $M_{c}$, the increments of model parameters at the $(k+1)$ th iteration $\delta \boldsymbol{m}_{k+1} \in \mathbb{R}^{M_{\rho}+M_{c}}$ is calculated by the equation

$$
\begin{aligned}
& \delta \boldsymbol{m}_{k+1}=\left(\overline{\boldsymbol{R}}^{T} \overline{\boldsymbol{R}}\right)^{-1} \overline{\boldsymbol{d}}-\left(\overline{\boldsymbol{R}}^{T} \overline{\boldsymbol{R}}\right)^{-1}\left(\boldsymbol{W} \overline{\boldsymbol{J}}_{k}\right)^{T} \overline{\boldsymbol{\Gamma}}_{k}^{-1}\left(\boldsymbol{W} \overline{\boldsymbol{J}_{k}}\right) \\
& \times\left(\overline{\boldsymbol{R}}^{T} \overline{\boldsymbol{R}}\right)^{-1} \overline{\boldsymbol{d}} \\
& \overline{\boldsymbol{d}}=- \overline{\boldsymbol{R}}^{T} \overline{\boldsymbol{R}} \boldsymbol{m}_{\rho, k}+\left(\boldsymbol{W} \overline{\bar{J}_{k}}\right)^{T} \boldsymbol{W}\left(\boldsymbol{d}-\boldsymbol{F}\left(\boldsymbol{m}_{\rho, k}\right)\right) \\
& \overline{\boldsymbol{\Gamma}}_{k}=\boldsymbol{I}+\left(\boldsymbol{W} \overline{\boldsymbol{J}_{k}}\right)\left(\overline{\boldsymbol{R}}^{T} \overline{\boldsymbol{R}}\right)^{-1}\left(\boldsymbol{W} \overline{\boldsymbol{J}_{k}}\right)^{T} \\
& \overline{\boldsymbol{R}}=\left(\begin{array}{cc}
\alpha \boldsymbol{R} & 0 \\
0 & \beta \boldsymbol{I}
\end{array}\right),
\end{aligned}
$$

where $\overline{\boldsymbol{J}_{k}} \in \mathbb{R}^{N \times\left(M_{\rho}+M_{c}\right)}$ is the sensitivity matrix including the derivatives of data with respect to the distortion matrices and $\beta \in \mathbb{R}$ is the trade-off parameter for the regularization term of the distortion matrices. This equation is calculated in the same way as solving eq. (7). The modified method is equivalent to the original model-space method.

\subsection{Synthetic data test}

We confirmed that the modified inversion method gives a result equivalent to that obtained by the original method in much less computational time by performing an inversion for the synthetic data using both methods. The target model was the model used in the synthetic case II of Siripunvaraporn et al. (2005). It consists of a conductive $(1 \Omega \mathrm{m})$ block and resistive $(100 \Omega \mathrm{m})$ block buried in a $10 \Omega \mathrm{m}$ horizontal layer and the underlying $100 \Omega \mathrm{m}$ layer (Fig. 2). The 64 observation sites were set on the surface of the model, which are marked as solid dots in Fig. 2. The full components of the impedance tensors for 16 periods from 0.1 to $1000 \mathrm{~s}$ were used as the data in the calculation, and the total number of data (real and imaginary part of the response function) was 8192. Gaussian random noises were added to all impedance tensor components of the synthetic data. The standard deviation of the noise was set to 5 per cent of the maximum amplitude of the off-diagonals, that is, $0.05 \times \max \left(\left|Z_{x y}\right|,\left|Z_{y x}\right|\right)$, where $Z_{x y}$ and $Z_{y x}$ denote the $x y$ and $y x$ components of the impedance tensor, respectively. The size of the computational mesh used in the inversion was $1000 \times 1000 \times$ $1100 \mathrm{~km}$, of which the uppermost $100 \mathrm{~km}$ was the air layer and the model was discretized with 619070 tetrahedral elements. All the elements, except for those of the air layer, were grouped into 59027 parameter cells by the algorithm written in Usui (2015). It should be noted that the computational mesh used to calculate the synthetic data was different from that used for the inversion, in which there were no pre-defined boundaries of the resistivity anomalies. Galvanic distortion was not considered in the calculation, and the trade-off parameter $\alpha^{2}$ was set as 10.0. The initial resistivities of the parameter cells were $100 \Omega \mathrm{m}$. The small value $\epsilon$ added to the diagonals of the roughening matrix was 0.0001 . The calculation was performed using the computer systems of the Earthquake Information Center of the Earthquake Research Institute, University of Tokyo (Xeon E5-4627 v2@3.3 GHz, $512 \mathrm{~GB}$ ), and four MPI processes and eight OpenMP threads per process were used in each calculation.

After the seventh iteration of the Gauss-Newton method, convergent solutions were obtained by both the original and the modified method. Both the rms misfit of the result of the original method and the one of the modified method were 1.14. Fig. 2 shows that there was not any notable difference between the resistivity structures obtained by the two methods. Therefore, we confirmed that the modified method gives the same result with the original method. However, the new method was computationally more efficient than the original method in the phase in which new model parameters were calculated by solving the normal equation: the modified method required $73 \mathrm{~s}$ per iteration, whereas the original method required $2176 \mathrm{~s}$ per iteration. This confirmed that the calculation time can be reduced significantly by transformation from the modelspace method to the data-space method.

In that model-update phase, two procedures, the dense matrixmatrix multiplication needed to construct the coefficient matrix of the linear equation $\left(\left[\left(\boldsymbol{W} \boldsymbol{J}_{k}\right)^{T}\left(\boldsymbol{W} \boldsymbol{J}_{k}\right)+\alpha^{2} \boldsymbol{R}^{T} \boldsymbol{R}\right]\right.$ of eq. (1); $\boldsymbol{\Gamma}_{k}$ of eq. (6)) and the numerical factorization of the matrix, took up most of the calculation time. Due to the transformation to the data-space method, the calculation time per iteration was reduced from 1425 to $65 \mathrm{~s}$ for the former procedure, while 748 to $3 \mathrm{~s}$ for the latter. The speed-up of the former procedure was mainly attributed to the reduction of the number of multiplications and summations of floating-point numbers. Since both of the coefficient matrices of the model-space method and the data-space method are symmetric, it is necessary to calculate only the upper triangle part of them. The model-space method, then, requires $M \times(M+1) \times N$ floatingpoint operations for the multiplication of $\left(\boldsymbol{W} \boldsymbol{J}_{k}\right)^{T}$ and $\left(\boldsymbol{W} \boldsymbol{J}_{k}\right)$, where $M$ and $N$ indicate the number of model parameters and data, respectively. On the other hand, the data-space method requires $N \times(N+1) \times M$ floating-point operations for the multiplication of $\left(\boldsymbol{W} \boldsymbol{J}_{k}\right)$ and $\left(\alpha^{2} \boldsymbol{R}^{T} \boldsymbol{R}\right)^{-1}\left(\boldsymbol{W} \boldsymbol{J}_{k}\right)^{T}$. Hence, when $N$ is less than $M$, the data-space method needs less floating-point operations. In addition, in the procedure, the use of multiple MPI processes in the data-space method also contributed the speed-up (it took $217 \mathrm{~s}$ when only one process was used). On the other hand, the speed-up of the latter procedure was owing to the decrease of the dimension of the coefficient matrix to be factorized. The dimension of the coefficient matrix of the data-space method is $N$ while that of the model-space method is $M$. Since the number of the floating-point operations required by the numerical factorization with LAPACK 

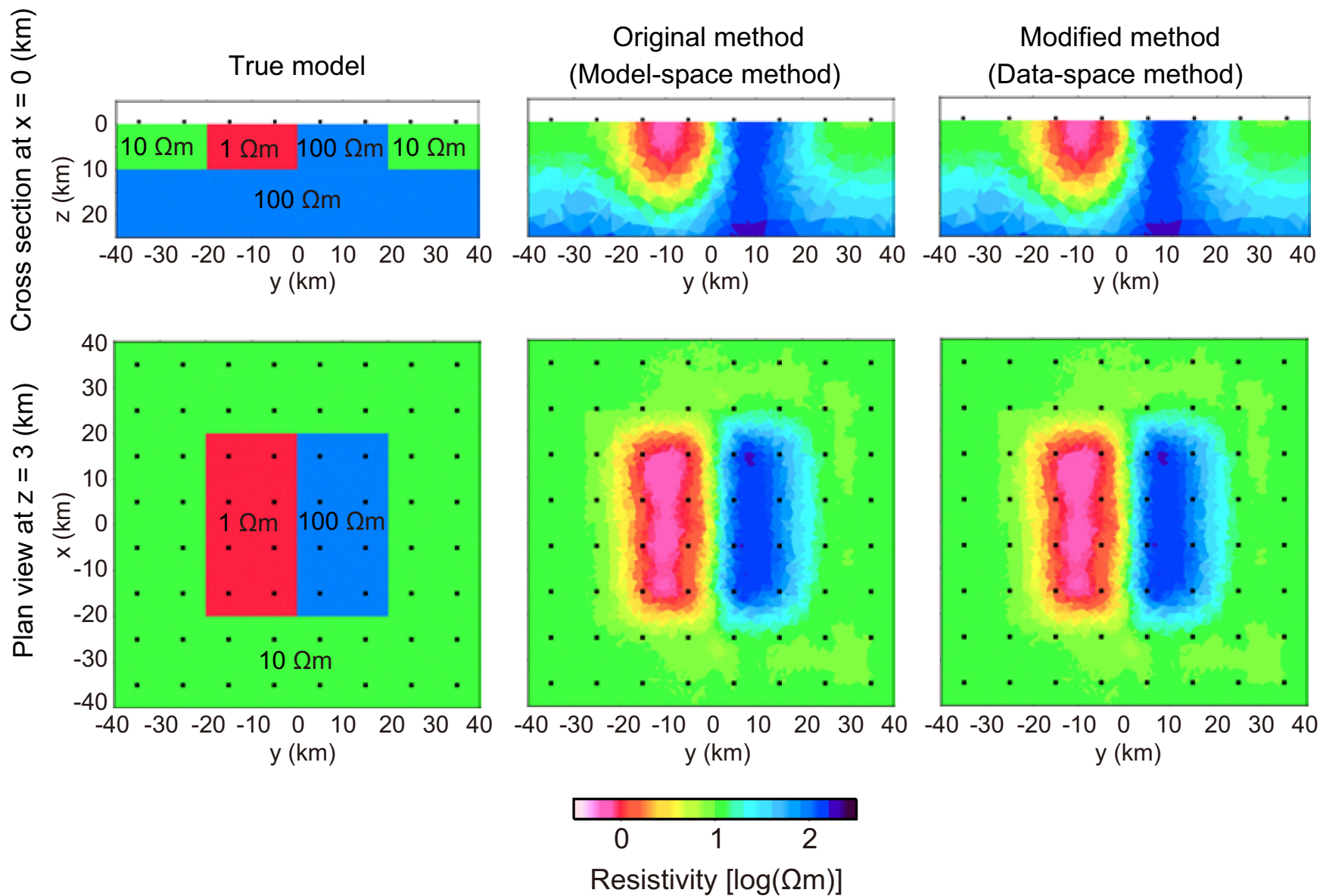

Figure 2. Comparison of the resistivity structures obtained by the original (model-space) method with those obtained by the modified (data-space) method. The upper figures are vertical cross-sections through the centre, and the lower figures are map views at $3 \mathrm{~km}$ in depth. The leftmost figures indicate the true resistivity structure. Figures adjacent to them (the middle panel) were drawn from the result obtained by the original method, whereas the rightmost panel indicates the results obtained by the modified method. The observation points are shown by dots in all sections.

(Anderson et al. 2000) is proportional to the cube of the dimension of the matrix, the calculation time was reduced significantly by the transformation to the data-space method when $N$ is less than $M$.

In addition, we compared the computation time of the forward calculation part of our code to that of a 3-D code using a hexahedral mesh. Kordy et al. (2016a) reported the computational times required for their inversion code using unstructured hexahedral elements, in which MKL PARDISO was used in the forward calculation as in our inversion code. The computational times for the reordering and for the factorization in a forward calculation for a hexahedral mesh with 734820 degrees of freedom were 17 and $60 \mathrm{~s}$, respectively, and the solving time for 100 right-hand sides was $11 \mathrm{~s}$, when the calculation was done with 24 cores. When we performed the forward calculation for the unstructured tetrahedral mesh of the synthetic test described above, which had 712922 degrees of freedom, with 24 cores following to Kordy et al. (2016a), the times for reordering and factorization were 9 and $37 \mathrm{~s}$, respectively, and the solving time for 100 right-hand sides was $15 \mathrm{~s}$. Thus, there was no difference of more than two times between the calculation times of the forward part for the unstructured tetrahedral mesh and for the unstructured hexahedral mesh reported in Kordy et al. (2016a). However, further researches are needed to conclude that the required calculation time for an unstructured tetrahedral mesh is comparable in a general way to that for an unstructured hexahedral mesh with similar degrees of freedom because it depends on the performance of the computer system, computational mesh and other calculation conditions.

\section{METHOD}

\subsection{Observational data}

In this study, the response functions estimated by Aizawa et al. (2008) were used although the data recorded at the three observation sites were not used since they were noisy (one audiomagnetotelluric (AMT) site and one MT site at the north of the volcano, which were more than $5 \mathrm{~km}$ away from the summit, and the southernmost AMT site). The measurement sites used in this study consisted of 36 MT sites and 37 AMT sites (Fig. 1). Of the former sites, 15 sites were two-channel MT (2E) sites and measured only electric fields. Except for the 2E sites, both impedance tensors and vertical magnetic transfer functions (VMTFs) were estimated. On the other hand, at the $2 \mathrm{E}$ sites, only impedance tensors were estimated by using the magnetic field of another MT site. At every site, response functions at about four periods per decade were used.

For the MT sites, the frequency range used in the inversion was from 320 to about $0.094 \mathrm{~Hz}$, whereas the frequencies ranged from 1300 to $0.59 \mathrm{~Hz}$ for the AMT sites. In addition, VMTFs lower than $10 \mathrm{~Hz}$ were not used at AMT sites as in Aizawa et al. (2008). The number of data (real and imaginary part of response function) used in the inversion was 8472 . The error floor of each impedance tensor 
(a) Overall view

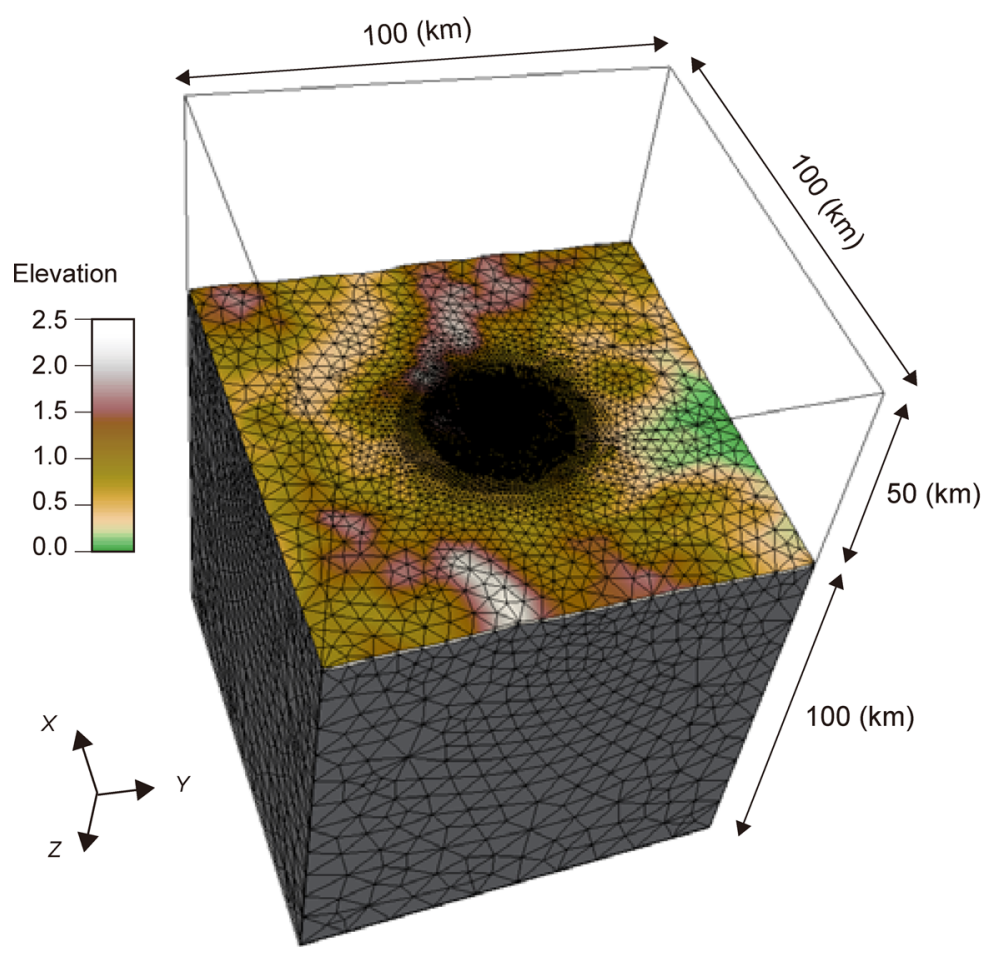

(b) Land surface around the survey area

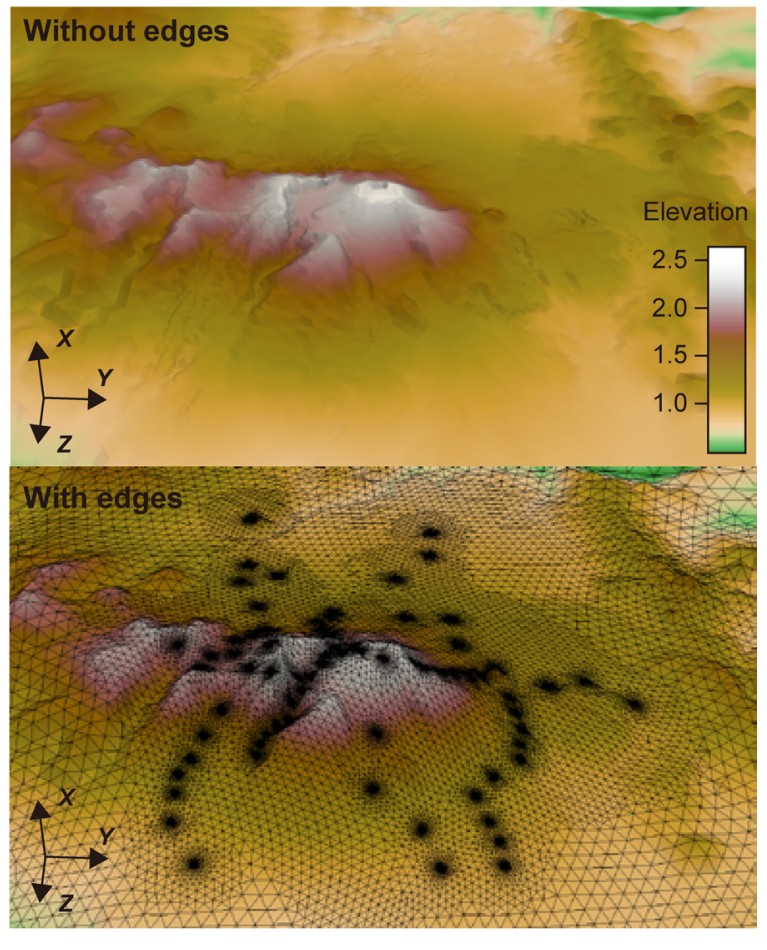

Figure 3. Computational mesh used in the 3-D inversion. The horizontal centre of the mesh was the summit of Asama Volcano, and the positive $x$-axis corresponds to the northern direction. (a) Overall view. Elements of the air layer are omitted to improve visibility of the Earth's surface within the mesh. (b) Surface mesh around the survey area. Edges of elements shown in the lower figure are omitted from the upper figure. Around the observing sites, mesh sizes are locally refined and edge lengths are shortened to approximately $10 \mathrm{~m}$ around the sites. Height differences around the mountainous area are emphasized by enlarging the vertical coordinates 1.5 times.

component was 5 per cent of the largest absolute value of the offdiagonals, that is, if the error of an impedance tensor component was less than $0.05 \times \max \left(\left|Z_{x y}\right|,\left|Z_{y x}\right|\right)$, it was force to be $0.05 \times$ $\max \left(\left|Z_{x y}\right|,\left|Z_{y x}\right|\right)$. The error floor of each VMTF component was 5 per cent of the maximum absolute values of its components, that is $0.05 \times \max \left(\left|T_{z x}\right|,\left|T_{z y}\right|\right)$ where $T_{z x}$ and $T_{z y}$ denote the $x$ and $y$ components of the VMTF, respectively. In addition, when the error of a VMTF component was smaller than 0.05 , it was set to 0.05 .

\subsection{Computational mesh with precise topography}

In this study, the influences of the topography are incorporated in the inversion model with the aid of unstructured tetrahedral elements. The computational mesh is shown in Fig. 3. The size of the mesh was $100 \mathrm{~km} \times 100 \mathrm{~km} \times 150 \mathrm{~km}$, of which the uppermost $50 \mathrm{~km}$ is the air layer. The horizontal centre of the mesh was the summit of Asama Volcano. Whereas the lengths were approximately $5 \mathrm{~km}$ at the outermost region, the edge lengths were shortened when approaching the observation sites and were scaled down to about $500 \mathrm{~m}$ within $15 \mathrm{~km}$ radius from the summit of Asama Volcano and about $200 \mathrm{~m}$ within $5 \mathrm{~km}$ radius from the summit. Furthermore, within $50 \mathrm{~m}$ from each observation site, the edge lengths are approximately $10 \mathrm{~m}$.

The total number of elements was 1140072 . All the elements, except those of the air layer, were distributed into 195607 parameter cells by the algorithm used in Usui (2015). Since parameter cells located in the uppermost $3 \mathrm{~km}$ around the survey area consist of at most only a few elements, the resolution of the resistivity distribution around the area is considered to be sufficiently high. In the deeper part, more elements constitute a parameter cell, however, we think it is reasonable because the electromagnetic field diffuses and attenuates as the depth increases, which causes the lower sensitivity to resistivity structure.

The mesh was created by the following two steps. First, the surface mesh covering the computational domain was generated. In the surface mesh, the top, bottom and sides of the computational domain were defined as well as the Earth's surface. The last of these surfaces was the inner surface, where precise topography was represented. All of the surfaces consist of triangles and they were created by the Delaunay triangulation method (Cheng et al. 2012). The surfaces were produced by first generating a mesh consisting of 2-D triangles, and then the heights ( $z$-coordinates) of the points of the 2-D mesh were interpolated from the $10 \mathrm{~m}$ grid digital elevation model of Fundamental Geospatial Data developed by GSI-Japan (Geospatial Information Authority of Japan 2011) and ETOPO1 (Amante \& Eakins 2009); the former was used in the area around Asama Volcano (Longitude: E138.25 $-\mathrm{E} 138.75^{\circ}$, Latitude: $\mathrm{N} 36.25^{\circ}-\mathrm{N} 36.58^{\circ}$ ), whereas the latter was used in the other areas. Next, the 3-D mesh was generated with the aid of a tetrahedral mesh generator TetGen ( $\mathrm{Si} 2007$ ) by using the surface mesh as piecewise linear complexes. When generating the mesh, the inputted surface mesh was preserved, that is, the Steiner points (automatically generated points) were only inserted in the interior space of the surface mesh.

\subsection{Calculation conditions of inversion}

To calculate response functions in inversion, tangential components of electric fields were used while horizontal components were used for magnetic fields. The different locations of electric and magnetic 
fields of the $2 \mathrm{E}$ sites were taken into account in the inversion. The initial subsurface resistivity was $10 \Omega \mathrm{m}$. Even if the initial subsurface resistivity was set to $100 \Omega \mathrm{m}$, this had little influence on the result. The small value added to the diagonals of the roughening matrix was set to 0.0001 as in the synthetic test of the previous section. In the inversion, the two-step approach was used to estimate both the subsurface resistivity values and the components of the distortion matrices as in Kordy et al. (2016b). First, only subsurface resistivity values were estimated (the first step) until the Gauss-Newton iteration converged. Next, adding the components of distortion matrices to unknown model parameters, the Gauss-Newton iteration was restarted (the second step).

The trade-off parameter $\alpha^{2}$ was selected by the L-curve criteria from the results obtained by six different $\alpha^{2 \prime} \mathrm{s}(1.00,3.16,10$, 31.6, 100 and 316) as in previous work (e.g. Patro et al. 2005; Matsuno et al. 2014). The L-curve and the optimal trade-off parameter that were obtained are presented in the next section. On the other hand, the value of the other trade-off parameter $\beta^{2}$ was set to be 0.01 since Avdeeva et al. (2015) and Kordy et al. (2016b) showed that the resistivity structure can be estimated properly with such a small trade-off parameter. Furthermore, it was confirmed that when $\beta^{2}$ was changed to be 0.1 , the estimated resistivity structures were rarely different. Even if the components of the distortion matrix were not estimated in the inversion, the rms misfit was only 10 per cent larger than for the case in which these components were estimated as model parameters. Therefore, the data set used in this study was not considered to be significantly affected by galvanic distortion.

\section{THREE-DIMENSIONAL RESISTIVITY STRUCTURE}

Converged solutions were obtained for all of the six different tradeoff parameters $\alpha^{2}$. The calculation time taken to update the model parameters in each iterative cycle was about $400 \mathrm{~s}$ using eight MPI processes and eight OpenMP threads per process for the same computer system that was used in the synthetic test. As it took about $60000 \mathrm{~s}$ when the original model-space inversion (Usui 2015) was used, the calculation time was dramatically reduced by the transformation to the data-space method. Fig. 4 shows the L-curve drawn from the data misfit and model roughness of these results. From the figure, the point corresponding to the model of $\alpha^{2}=10.0$ appears to be the 'knee' of the curve, that is, the most preferable model. Therefore, we selected the model of $\alpha^{2}=10.0$, whose rms was 1.108 , as the best model. Figs 5 and 6 compare the observed response functions with the ones calculated from the best model. The apparent resistivity and the phase of the determinant impedance tensor for the representative frequency ranges are compared in Fig. 5, whereas the induction arrows are compared in Fig. 6. These figures illustrate that, overall, the best model explains the observed data. In the following, the characteristic features of the best model are shown.

Fig. 7 shows the vertical cross-sections of the 3-D resistivity structure along the profiles of the 2-D inversions that were previously determined by Aizawa et al. (2008). As with the result of the previous study, the obtained resistivity structure of the 3-D inversion has a resistive $(>100 \Omega \mathrm{m})$ surface layer and an underlying conductive layer $(<5 \Omega \mathrm{m})$. At the westernmost profile (Line-A) and the profile through the horseshoe-shaped caldera (Line-B), the obtained resistivity distributions are similar to those of Aizawa et al. (2008) although the conductors of the 2-D model appear to have slightly

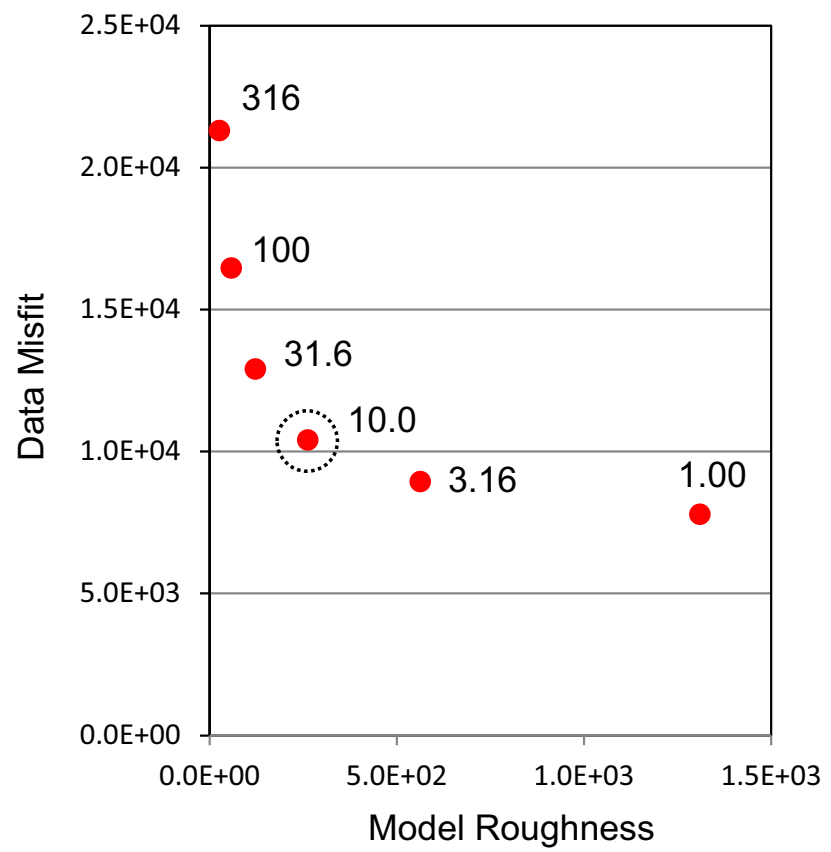

Figure 4. L-curve obtained from the results of the 3-D inversions with various trade-off parameters. The horizontal and vertical axes represent the model roughness term and data misfit term of the objective function, respectively. The numbers adjacent to the points indicate the value of parameter $\alpha^{2}$ giving the corresponding result. The point surrounded by a dotted circle corresponds to the best model selected in the present study $\left(\alpha^{2}=10.0\right)$.

lower resistivities. At Line-A, the resistive area (R1) is found near the crossover point to the $\mathrm{E}-\mathrm{W}$ profile and is sandwiched between more conductive layers ( $\mathrm{C} 1$ and $\mathrm{C} 2$ in Fig. 7a). At about $1 \mathrm{~km}$ below the ground surface of the crossover point of Line-B, there is a circular resistor of about $30 \Omega \mathrm{m}$ (R2) under the 24 ka collapse caldera (Fig. 7b).

Nam et al. (2007) calculated the MT response functions along the centre line of a 3-D trapezoidal hill using a computational mesh with the 3-D topography, and compared them with those obtained by the 2-D forward calculation in which only the topography parallel to the profile was included in the mesh (Wannamaker et al. 1986). They revealed that the TM-mode apparent resistivity obtained by the 2-D calculation was not much different from that obtained by the 3-D calculation while, in TE mode, the 2-D calculation did not reproduce the decrease of the TE-mode apparent resistivity on the hill obtained by the 3-D calculation. Since Line-A and Line-B are approximately perpendicular to the level line of Asama-Eboshi Volcanoes, the topographic effect to the TM-mode responses might have been adequately modelled by the mesh with the 2-D topography. On the other hand, it can be presumed that the topographic effect to the TE-mode responses, which could not be represented by the 2-D mesh, made the resistivity values around the summit area to be underestimated than the real values. Furthermore, the 2-D resistivity structures of Aizawa et al. (2008) were estimated using the 2-D inversion code developed by Ogawa \& Uchida (1996). The 2-D code utilizes the finite-element method as our inversion code does, and the regularization functional of the 2-D code is similar to that of our 3-D code: the roughening matrix of the 2-D code gives the difference of the log-resistivity of each parameter cell from the average log-resistivity of its surroundings as that of our code and both codes do not use prior models for the regularization. Similarity to the resistivity structures of Aizawa et al. (2008) seen in our 
Apparent resistivity
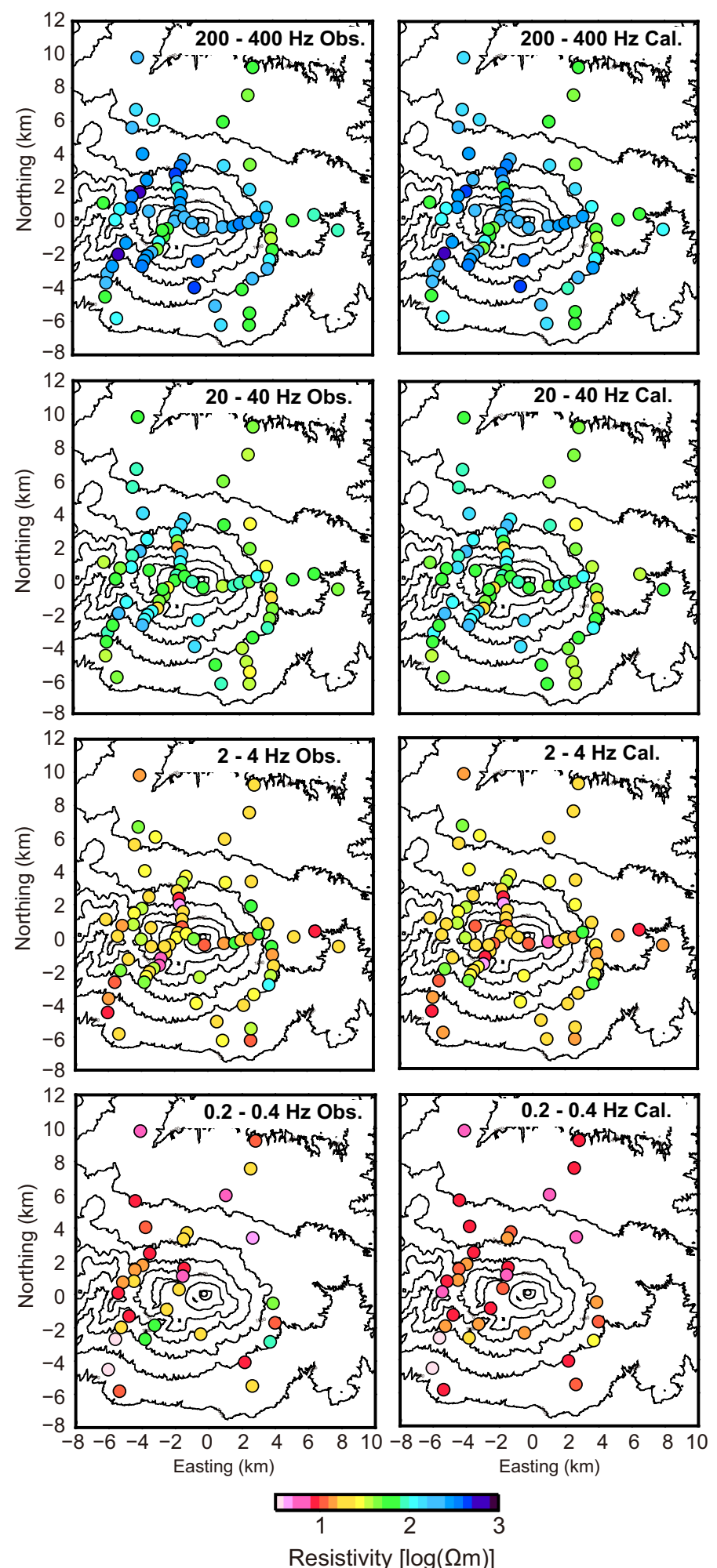

Phase
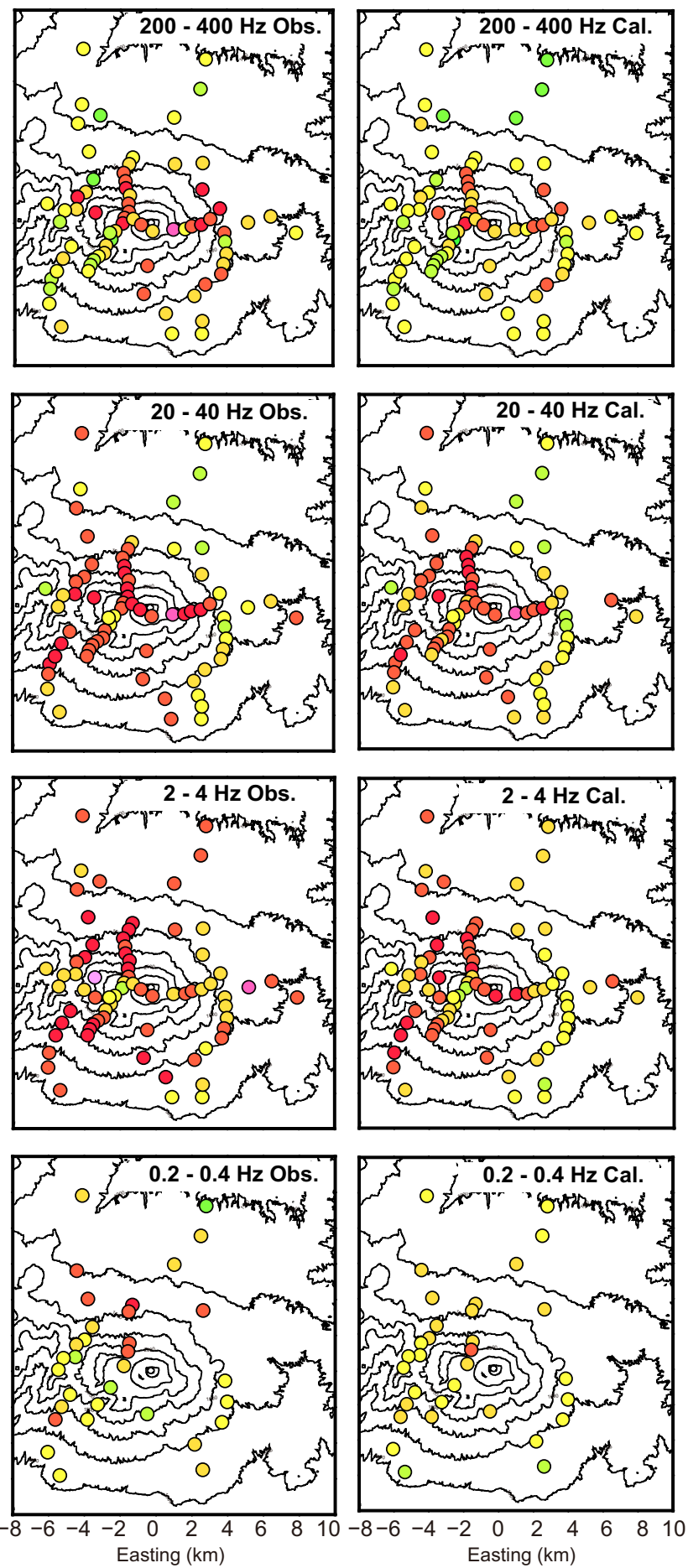

$0 \quad 153045607590$

Phase [deg]

Figure 5. Maps for comparison of observed data (Obs.) with calculated responses (Cal.). The apparent resistivity and phase of the determinant impedance tensor are shown. Frequencies at which response functions were estimated are not the same at all observation sites; thus, representative frequencies are indicated as ranges instead of fixed values.

results could have been obtained also by this similarity of modelling technique.

On the other hand, at the easternmost $\mathrm{N}-\mathrm{S}$ profile (Line-C) and the E-W survey line (Line-EW), there are notable differences between the resistivity structures of this study and those of Aizawa et al. (2008). At Line-C (Fig. 7c), the resistivity structure of this study is smoother than that of Aizawa et al. (2008). Therefore, it is presumed that some of the 3-D effects were responsible for artificially 

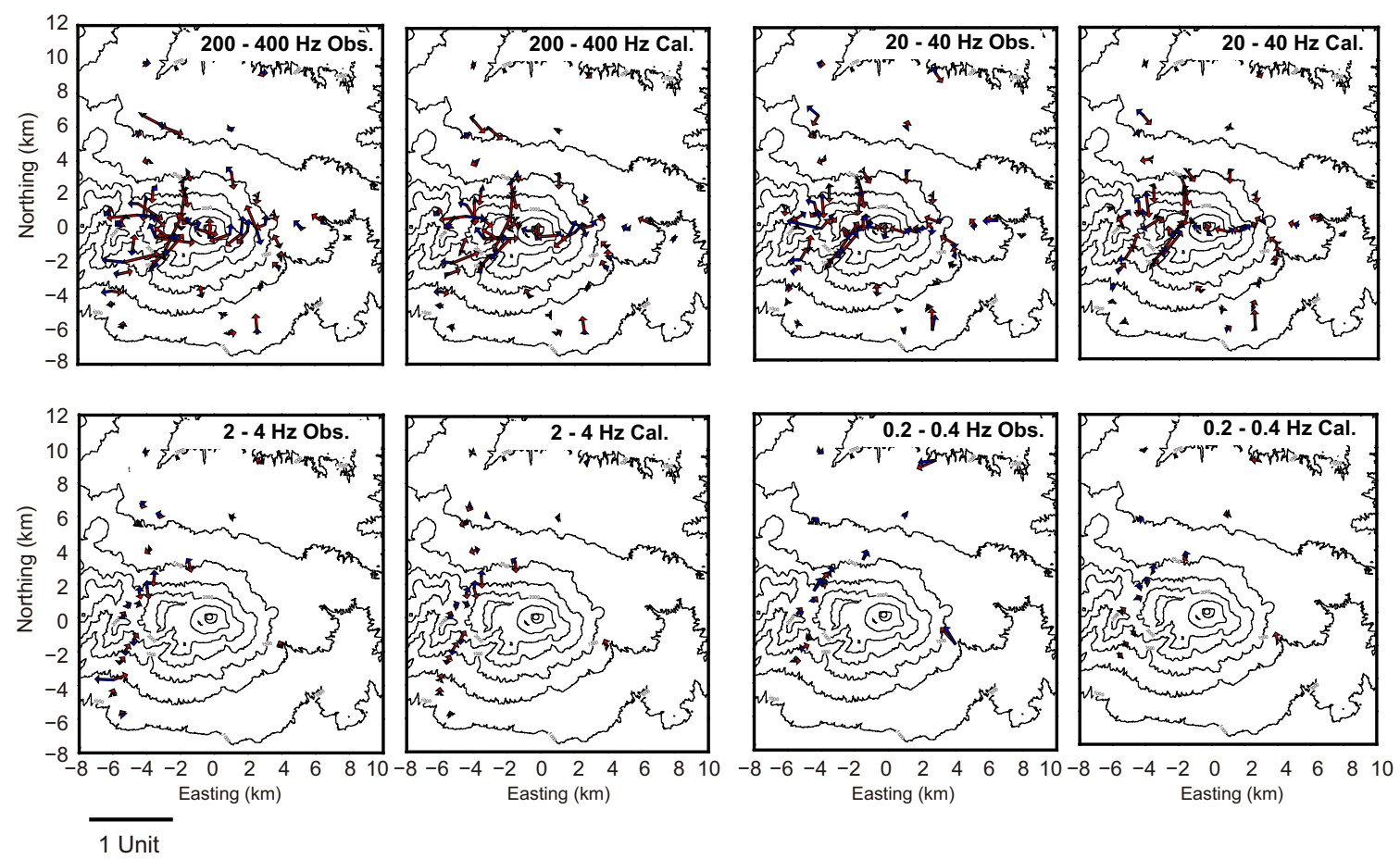

Figure 6. Induction vectors (Parkinson convention) for the comparison of observed data (Obs.) with calculated response functions (Cal.). Red and blue arrows indicate real and imaginary vectors, respectively.

creating a rougher structure inferred from the 2-D inversion along this profile. In the resistivity structure obtained by this study, the conductive layer $(\mathrm{C} 1)$ is widely spread along Line-C, particularly in its northern part. The conductive area found by the 2-D study along Line-EW is located several hundred metres shallower than the corresponding conductor inferred from this study (Fig. 7d), and shows the resistivity value of almost a half of the 3-D conductor. In addition, in the 2-D analysis, the resistivity structure of LineEW was not consistent with those of Line-A and Line-B around the intersections. We guess 3-D topography and/or 3-D resistivity anomalies caused the inconsistency in the 2-D study. It should be noted that, along Line-EW, we can see a difference in the resistivity values between the eastern side of the presently active crater and its western side: the resistivity on the eastern side at about $1 \mathrm{~km}$ below sea level (BSL) is lower than that on the western side.

The horizontal section views of the 3-D resistivity structure are shown in Fig. 8. At altitudes from 0.5 to $1.5 \mathrm{~km}$ ASL, a circular resistive area (R2) can be found under the caldera, and this area corresponds to the resistive body found in the vertical cross-section along Line-B and Line-EW. Aizawa et al. (2008) inferred that the resistive body was isolated because a low-phase zone under the collapse caldera of Kurofu Volcano, that appeared not to be connected to the other surrounding low-phase zone, was found in the phase maps for several frequencies calculated from the determinant of impedance tensor. The 3-D inversion we performed enabled us to confirm that the resistive body is isolated. At depths ranging from $0.5 \mathrm{~km}$ BSL to $0.5 \mathrm{~km}$ ASL (Figs $8 \mathrm{~d}-\mathrm{f}$ ), a relatively high-resistivity area (R1) exists below the eastern end of the Eboshi Volcanoes, and this area corresponds to the sandwiched resistive area of Line-A (Fig. 7a). Fig. 8 shows that R1 seems to extend to beneath R2, although Aizawa et al. (2008) suggested that the resistive bodies of Line-A and Line-B exist in isolation. Therefore, we attempted to verify whether R1 and R2 are connected below sea level by performing a sensitivity test. Specifically, the resistivity of the area to the southeast of R1 (marked by the blue solid line in Fig. 8) was forced to be higher than or equal to $3 \Omega \mathrm{m}$ at a depth between $1.0 \mathrm{~km} \mathrm{BSL}$ and $1.0 \mathrm{~km}$ ASL (to be more precise, if the resistivity of a parameter cell whose gravity centre lies in that range was lower than $3 \Omega \mathrm{m}$, it was forced to be $3 \Omega \mathrm{m}$ ), and a forward calculation was performed for the model. The rms obtained by the forward calculation was 1.111; thus, it was quite similar to the original rms (1.108). Since only AMT sites were located over the area and there was shallower conductor $(<3 \Omega \mathrm{m})$ above the area, the data in this study had less sensitivity to the area. Therefore, it is unclear whether R1 and R2 are connected below sea level from the data in this study.

By performing the 3-D inversion using the mesh with precise topography, we succeeded in obtaining more plausible resistivity structure of Asama Volcano than that proposed by Aizawa et al. (2008), which was a first-order structure as described in that paper. As was pointed out above, the resistivity structures along Line$\mathrm{C}$ and Line-EW showed some differences between the previous 2-D study and this study. Although some of the features seen in the resistivity structure had already been suggested by the previous study, this study gave credibility to these features. Furthermore, this study provided the information about the horizontal distributions of resistivity anomalies, and revealed that conductive areas $(\mathrm{C} 1$ and C2) are widely distributed under the mountainous area.

\section{INTERPRETATION OF RESISTIVITY STRUCTURE}

Fig. 9 shows precisely relocated hypocentres of the earthquakes from 2004 January to 2015 January (M. Takeo 2015, unpublished data). These hypocentres are plotted over the resistivity structure. The distribution of the hypocentres is considered to indicate the magma pathway beneath Asama Volcano (Takeo et al. 2006; Aoki et al. 2013). The hypocentres are located around the spherical 
(a) Line-A

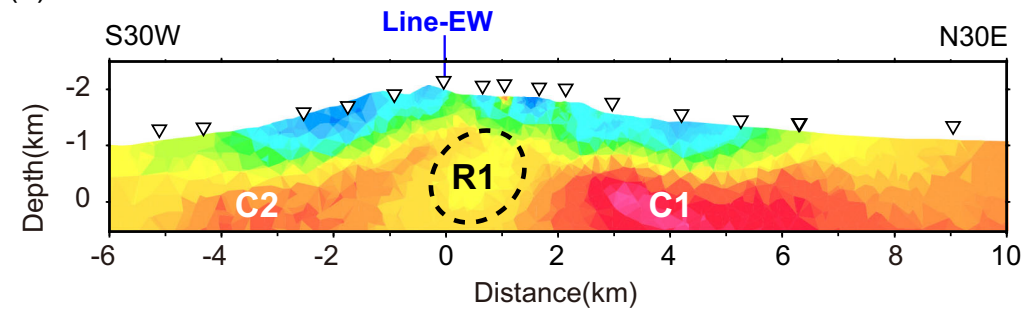

(b) Line-B
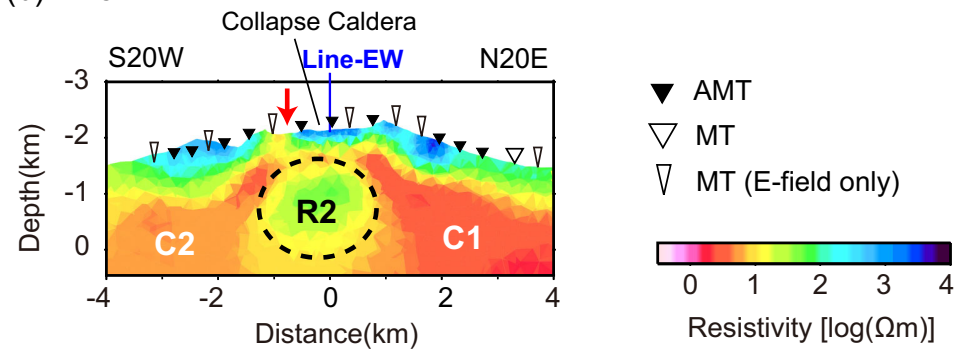

(c) Line-C

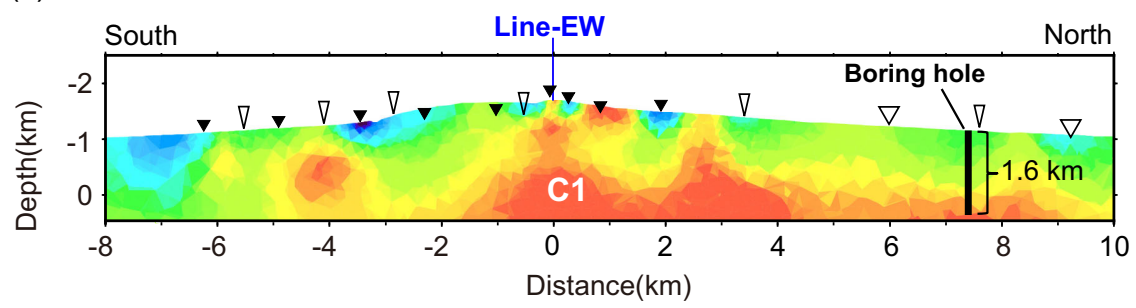

(d) Line-EW

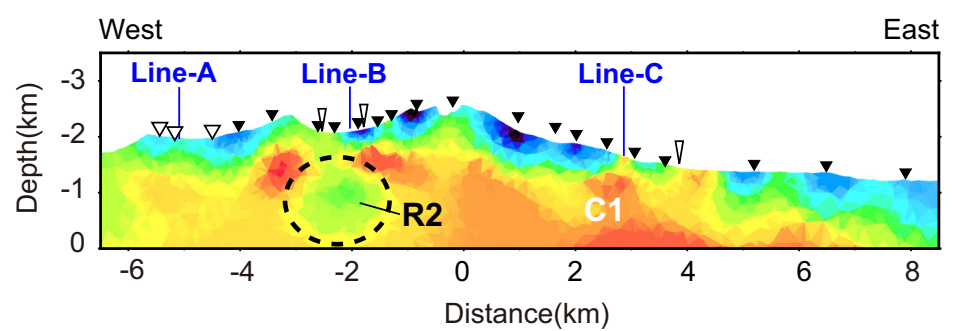

Figure 7. Vertical cross-sections of the 3-D resistivity structure along the profiles of Aizawa et al. (2008). (a) Cross-section along Line-A. (b) Cross-section along Line-B. (c) Cross-section along Line-C. (d) Cross-section along the E-W survey line (Line-EW). The locations of these profiles are shown in Fig. 8(a). Red arrow in (b) indicates the location of the Jigokudani fumarolic area, which corresponds approximately to the intersection of Line-B and the Tomi fault (Fig. 1). In addition, the location of a borehole for a commercial hot spring is indicated in (c).

resistive body below the collapse caldera (R2): horizontally distributed earthquakes are located below the resistive body and vertically distributed earthquakes are lined up to the east of the resistor. As with Aizawa et al. (2008), we interpret that the resistive body consists of old and solidified magma and it forces the ascending magma to move eastward to the present conduit. Such structural controls were also suggested for Iwate Volcano, Japan (Aizawa et al. 2009b), Aso Volcano, Japan (Kanda et al. 2008), Kirishima Volcanoes, Japan (Aizawa et al. 2014) and El Hierro Island (Canary Islands), Spain (Garcia-Yeguas et al. 2014). Because the resistive body is located beneath the centre of the old stratovolcano, repeated intrusions of magma under the old eruption centre might have reduced the connected porosity of the area, causing it to become highly resistive. On the other hand, resistive body R1 is located in the area of high $P$-wave velocity and high density revealed by Aoki et al. (2009), which coincides with the area of dyke intrusion during the 2004 eruptions (Takeo et al. 2006). Aoki et al. (2009) suggested that the high velocity is due to the solidification of repeatedly intruded magma since the slowly cooled magma becomes unfractured rock with high density and high seismic velocity. Thus, $\mathrm{R} 1$ is considered to also probably have lowered the connected porosity compared to the surrounding area, and is then imaged as a resistive area.

Next, we focus on the resistive layer directly beneath the land surface and the underlying conductive layer commonly found in the obtained resistivity structure. We interpret the resistive layer as an undersaturated zone. Since volcanoclastic rocks often have large connected porosity, the resistivity depends heavily on the water content. Therefore, for the layer to be resistive, its water content necessarily needs to be lower. On the other hand, the underlying conductive layers $(\mathrm{C} 1$ and $\mathrm{C} 2)$ are considered to have high water content and to be rich in altered clay minerals. In volcanic terrain, layer rich in altered clay minerals, especially smectite, is commonly considered to be a major cause of conductive anomalies (e.g. Ogawa et al. 1998; Ussher et al. 2000; Nurhasan et al. 2006; Aizawa et al. 2009a; Kanda et al. 2010; Yamaya et al. 2013). Morita et al. (2016) inferred from the diffuse $\mathrm{CO}_{2}$ mapping that the conductive area 
(a) $2.0 \mathrm{~km} \mathrm{ASL}$

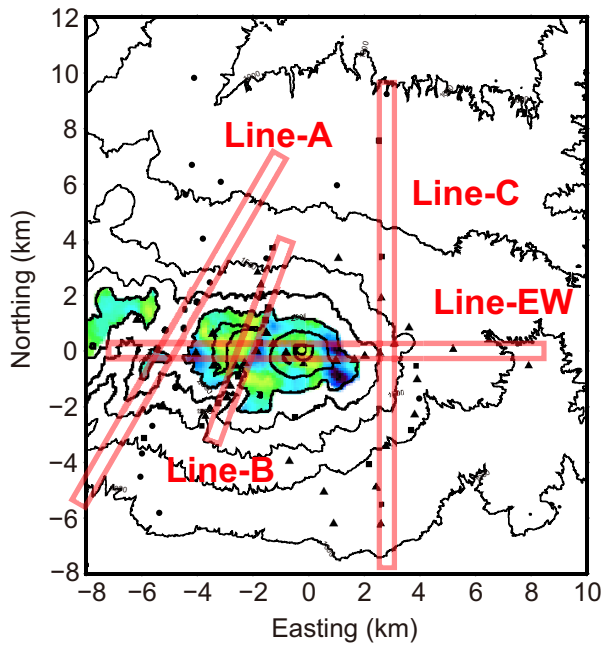

(d) $0.5 \mathrm{~km} \mathrm{ASL}$

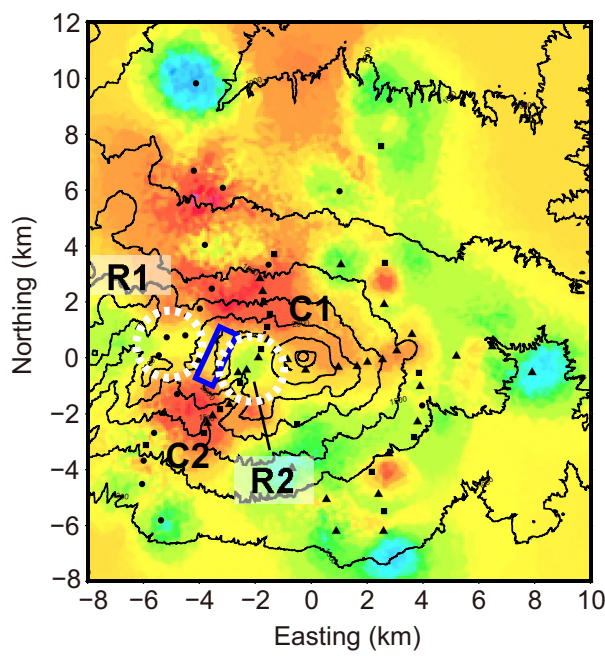

(b) $1.5 \mathrm{~km} \mathrm{ASL}$

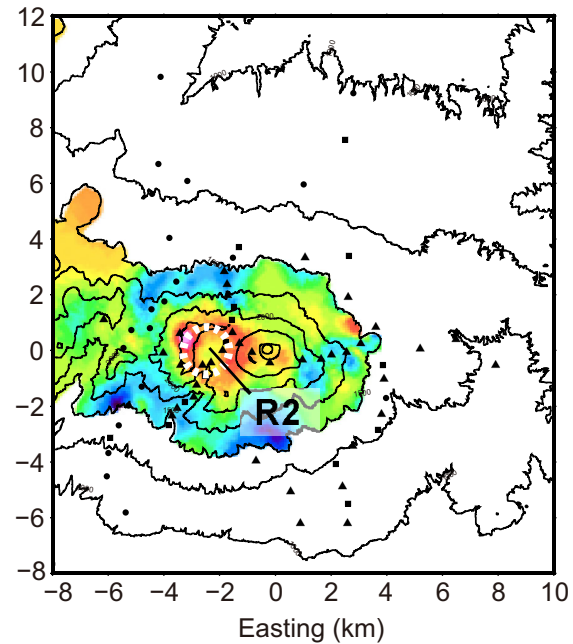

(e) Sea level

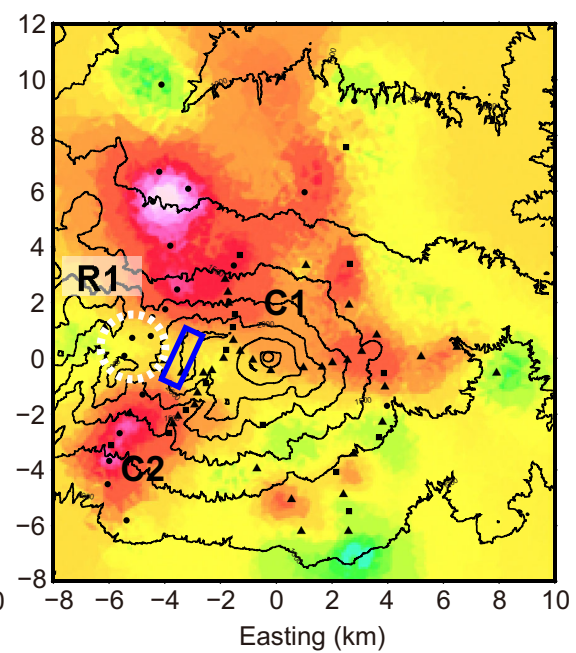

(c) $1.0 \mathrm{~km}$ ASL

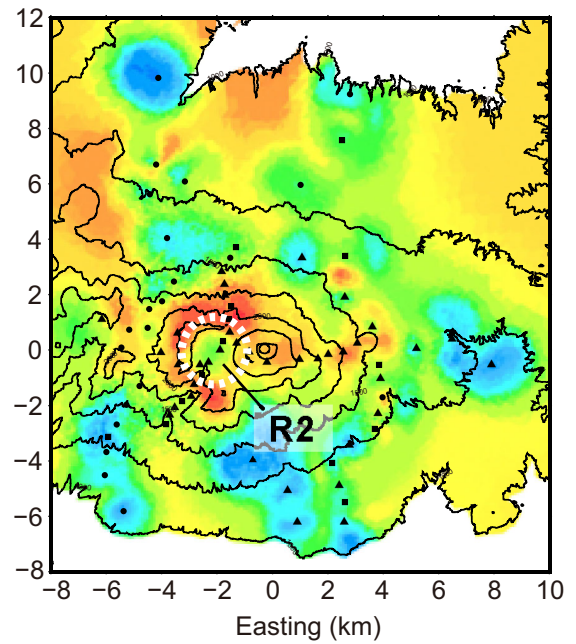

(f) $0.5 \mathrm{~km} \mathrm{BSL}$

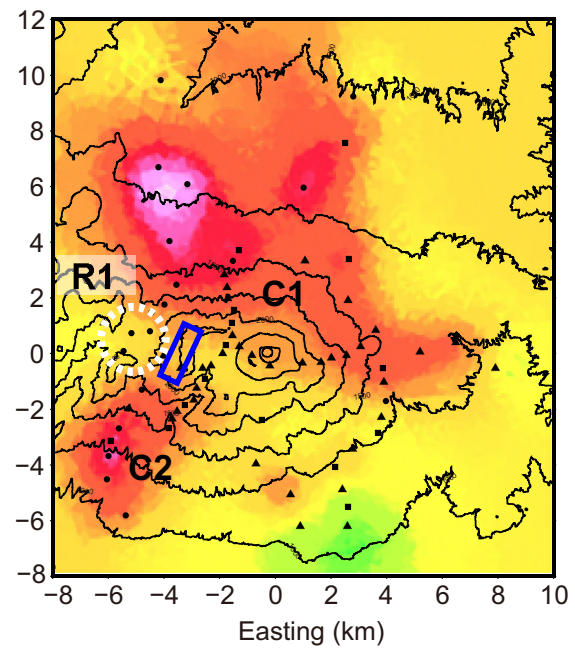

- AMT Stations

- MT Stations

- MT Stations (E-field only)

Figure 8. Horizontal cross-sections of the resistivity structure obtained by 3-D inversion. In (a), profiles of Aizawa et al. (2008) are also shown. The area of which the resistivity was changed to $3 \Omega \mathrm{m}$ for a sensitivity test is marked as a blue solid line in (d)-(f).

beneath the summit of Asama Volcano is constituted of to the uppermost clay-rich layer and the underlying hydrothermal fluid layer. Furthermore, there are several studies indicating the presence of high-water-content layer under Asama Volcano. Kazama et al. (2015) calculated the steady distribution of the unconfined groundwater level around Asama Volcano based on hydrological physics. They revealed that the groundwater level around the summit area is about $1.5 \mathrm{~km}$ ASL and becomes higher to the west, which is consistent with the top of the conductive layer. In addition, at a distance of $7 \mathrm{~km}$ along Line-C (Fig. 7c), a commercial hot spring with water at about $73^{\circ} \mathrm{C}$ is drawn from $1.6 \mathrm{~km}$ below ground (Aizawa et al. 2008). Fig. 7(c) shows that the bottom of the borehole corresponds to the conductive layer. In particular, around the summit area, it was suggested that there exist a hydrothermal system driven by the heat of magma (Aizawa et al. 2008; Morita et al. 2016). Near the intersection of Line-B and the Tomi fault, which is a normal fault cutting the southern part of the collapse caldera of Kurofu Volcano, a fumarolic area called Jigokudani is located (Figs 1 and 7b).
The volcanic gases rich in $\mathrm{SO}_{2}$ and $\mathrm{CO}_{2}$ and the acid spring water ( $\mathrm{pH} 3-6)$ rich in $\mathrm{SO}_{4}{ }^{2-}$ are discharged from the fumarolic area (Aramaki 1963; Suzuki 2002). The resistivity just beneath the fumarolic area (about $10 \Omega \mathrm{m}$ ) is lower than the surroundings, and this low-resistivity area is connected to the conductive layer $\mathrm{C} 2$ (Fig. 7b). It appears that the volcanic fluids supplied from the underlying hydrothermal system to the fumarolic area through the fractures around the Tomi fault.

In addition to geophysical studies, geochemical studies were also performed around Asama Volcano. Suzuki (2002) analysed the chemical and isotopic compositions of 80 samples of spring water around the volcano and found that the spring water on the northern and eastern slopes have higher $\mathrm{SO}_{4}{ }^{2-}$ and $\mathrm{Cl}^{-}$concentrations than on the southern and western slopes (Fig. 10). Suzuki (2002) interpreted these results to mean that the spring water discharged at the northern and eastern feet originates from the groundwater affected by the sulphate-chloride thermal water formed beneath the presently active crater, and that the groundwater flows to the 


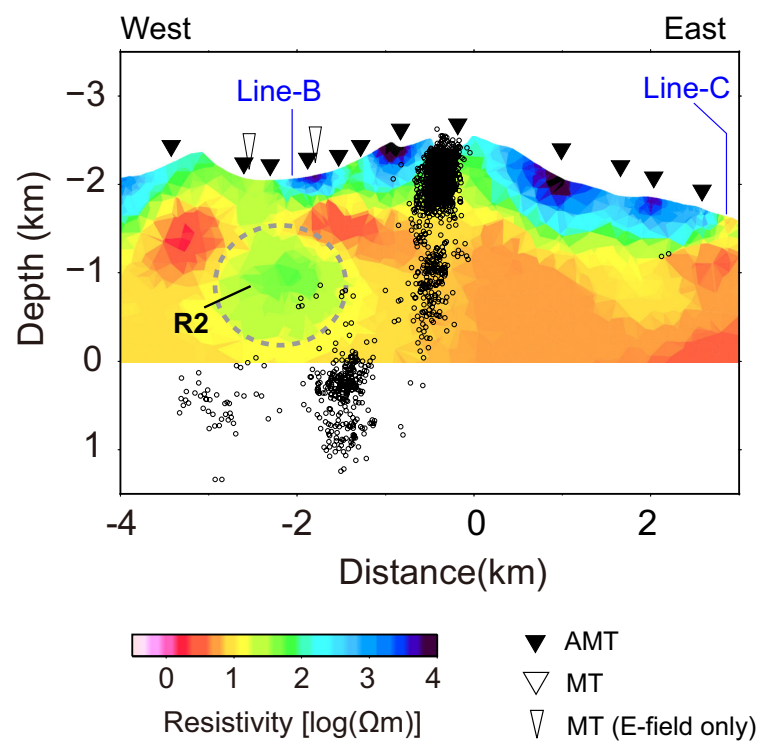

Figure 9. Comparison of the resistivity structure to the hypocentre distribution around Asama Volcano. On the vertical cross-section along Line-EW, precisely relocated hypocentres of earthquakes detected between 2004 January and 2015 January (M. Takeo 2015, unpublished data), within $\pm 500 \mathrm{~m}$ of the section, are plotted. The spherical resistive body beneath the collapsed caldera (R2) is marked by a broken circle.

(a) $\mathrm{SO}_{4}{ }^{2-}$ concentrations
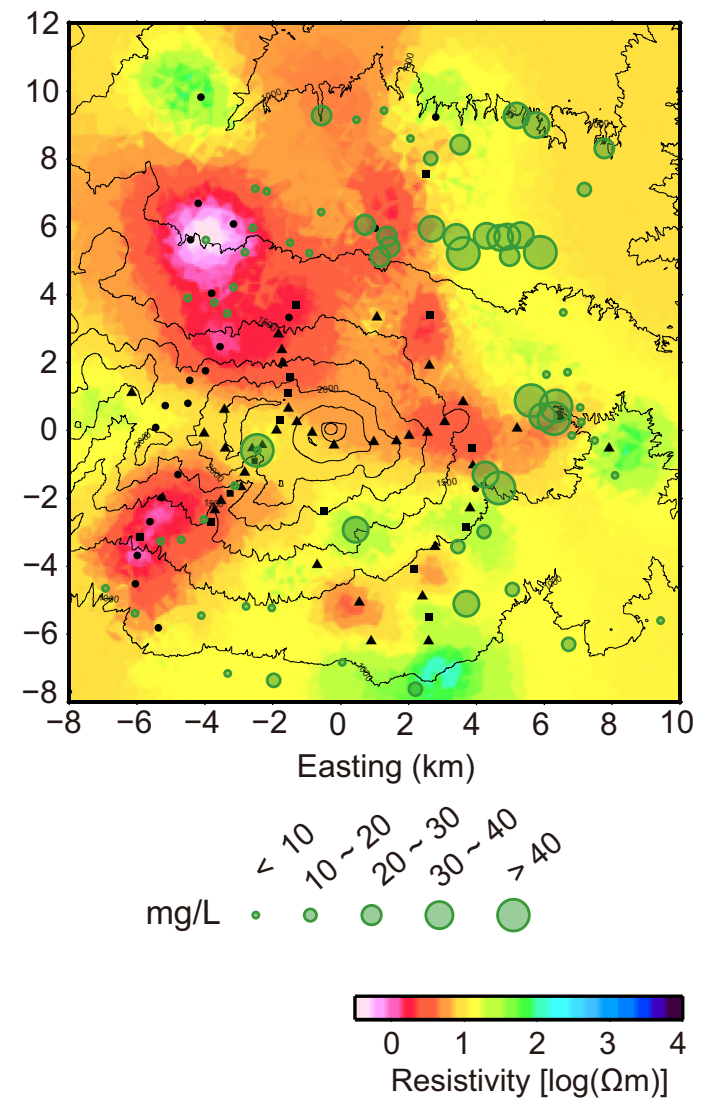

northern and eastern feet along the surface of the collapsed caldera of Kurofu Volcano. Kazama et al. (2015) also suggested that groundwater flows from the western side of Asama Volcano to the eastern flank through the volcanic conduit below the presently active crater. Furthermore, the helium isotope ratio of the hot spring water to the north of Line-C (Fig. 7c) suggests the contribution of magmatic fluids to the hot spring (Aizawa et al. 2008). Therefore, we suggested that the conductive layer extending from beneath the presently active crater to the northern and eastern area (C1) represents the highwater-content layer with the water affected by the hydrothermal water beneath the presently active crater. To the west of the volcanic conduit, there were resistive areas (R1 and R2), both of which were inferred to have low connected porosities, that is, low permeability (Farquharson et al. 2015). These resistive areas are considered to prevent groundwater from flowing to the west of the conduit and make the spring water rich in $\mathrm{SO}_{4}{ }^{2-}$ and $\mathrm{Cl}^{-}$eccentrically locates at the eastern and northern slopes.

In addition, Morita et al. (2016) observed the diffused $\mathrm{CO}_{2}$ and soil temperature around the summit area and revealed that highly diffuse $\mathrm{CO}_{2}$ anomalies were found only to the east of the present vent. They ascribed the heterogeneous distribution of diffuse $\mathrm{CO}_{2}$ to the different depths of the fluid layer. However, as in the case of the anion compositions discussed above, the differences among the connected porosities beneath the summit area may also contribute to the heterogeneous diffuse $\mathrm{CO}_{2}$ flux. That is, it would appear that the magmatic gases of the conduit flow preferentially into the eastern

\section{(b) $\mathrm{Cl}^{-}$concentrations}

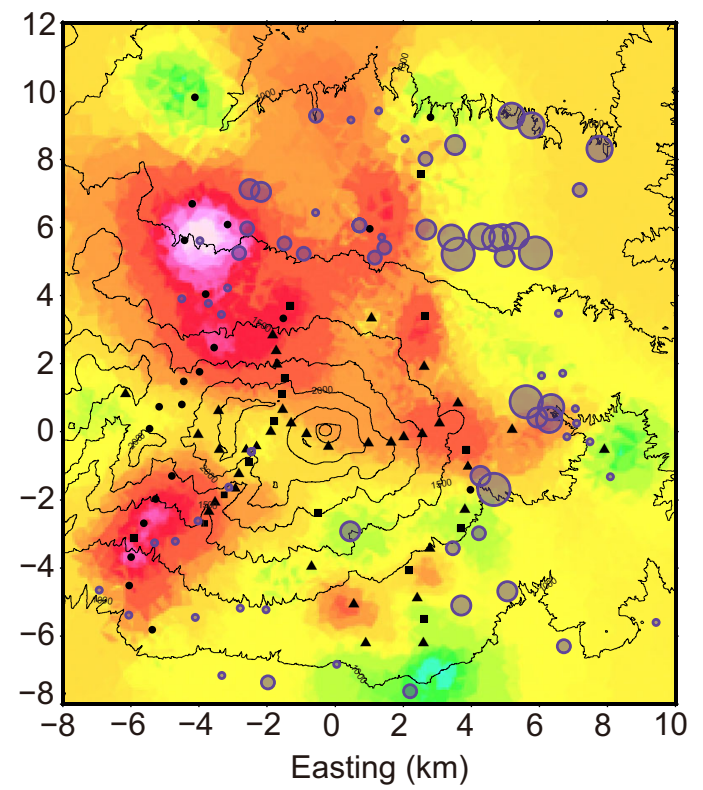

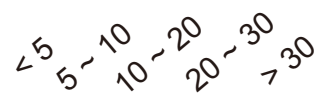

$\mathrm{mg} / \mathrm{L}$

\section{$\Delta$ AMT Stations \\ - MT Stations \\ - MT Stations (E-field only)}

Figure 10. Comparison of the resistivity structure at the sea level to the $\mathrm{SO}_{4}{ }^{2-}$ and $\mathrm{Cl}^{-}$concentrations of the spring water around Asama Volcano (Suzuki 2002). (a) $\mathrm{SO}_{4}{ }^{2-}$ concentrations. (b) $\mathrm{Cl}^{-}$concentrations. 
part, and may be responsible for the highly diffuse $\mathrm{CO}_{2}$ anomalies that are only found in the eastern part of the summit area.

Fig. 11 shows a schematic view of the relations between the resistive structure and the subsurface fluids. In the east-west direction, the feature of the subsurface resistivity structure changes beyond the volcanic conduit. To the west of the conduit, resistive areas (R1 and R2) exist below old eruption centres, which may have lower connected porosity than their surroundings due to the repeated intrusion of the magma from the underlying magma chamber. These resistive areas are likely to influence on the anion concentrations of the ground water and the heterogeneity of the diffuse $\mathrm{CO}_{2}$ flux around the summit area, which also varies beyond the conduit, by forcing magmatic gases and hydrothermal water to flow preferentially to the east and north of the active crater. By performing the 3-D inversion using the mesh with precise topography, we were able to infer the relationship between the resistive area formed by magma intrusion and the characteristic distributions of the $\mathrm{SO}_{4}{ }^{2-}$ and $\mathrm{Cl}^{-}$concentrations of the spring water and diffuse $\mathrm{CO}_{2}$ flux.

\section{CONCLUSIONS}

The resistivity structure around Asama Volcano was able to be revealed with the aid of an unstructured tetrahedral mesh with precise topography. In order to reduce the calculation time required to update unknown resistivities in inversion, we transformed the inverse problem from the model space into the data space. A synthetic test showed that the new method can significantly reduce the calculation time required to update model parameters while giving the same result with the original method. The resistivity structure determined around Asama Volcano was commonly characterized by a resistive layer directly beneath the land surface and the underlying conductors. The former was considered to consist of volcanoclastic rocks with low water content, whereas the latter was interpreted as comprising high-water-content and cray-rich layers. In addition, the feature of the resistivity structure changed in the east-west direction beyond the volcanic conduit below the crater that is presently active. To the west of the conduit, a spherical resistive body was found to exist beneath the old eruption centres, which would consist of unfractured rocks and prevent the volcanic gases and hydrothermal water beneath the active crater from flowing to the southwest of the conduit. Furthermore, it would contribute to the higher concentrations of $\mathrm{SO}_{4}{ }^{2-}$ and $\mathrm{Cl}^{-}$in the spring water discharged at the northern and eastern feet and would cause a diffuse $\mathrm{CO}_{2}$ flux anomaly to appear only to the east of the present crater. Therefore, by estimating the 3-D resistivity structure, we were able to infer the relationship between the unfractured area formed by magma intrusion, as found by geophysical studies, and the characteristic distribution of the anion concentrations of the spring water and the diffuse $\mathrm{CO}_{2}$ flux, as revealed by geochemical studies. The present work was the first application of 3-D MT inversion using unstructured tetrahedral elements to field-observed data, and demonstrated that it can provide sensible results with actual MT data.

\section{ACKNOWLEDGEMENTS}

We are grateful to the members of the Volcanic Fluid Research Center of the Tokyo Institute of Technology for their many helpful suggestions. We would like to sincerely thank Prof M. Takeo (the University of Tokyo) for providing us with the data of the precisely relocated hypocentres around Asama Volcano. We would like to express our gratitude to Dr H. Suzuki (Komazawa Univer-

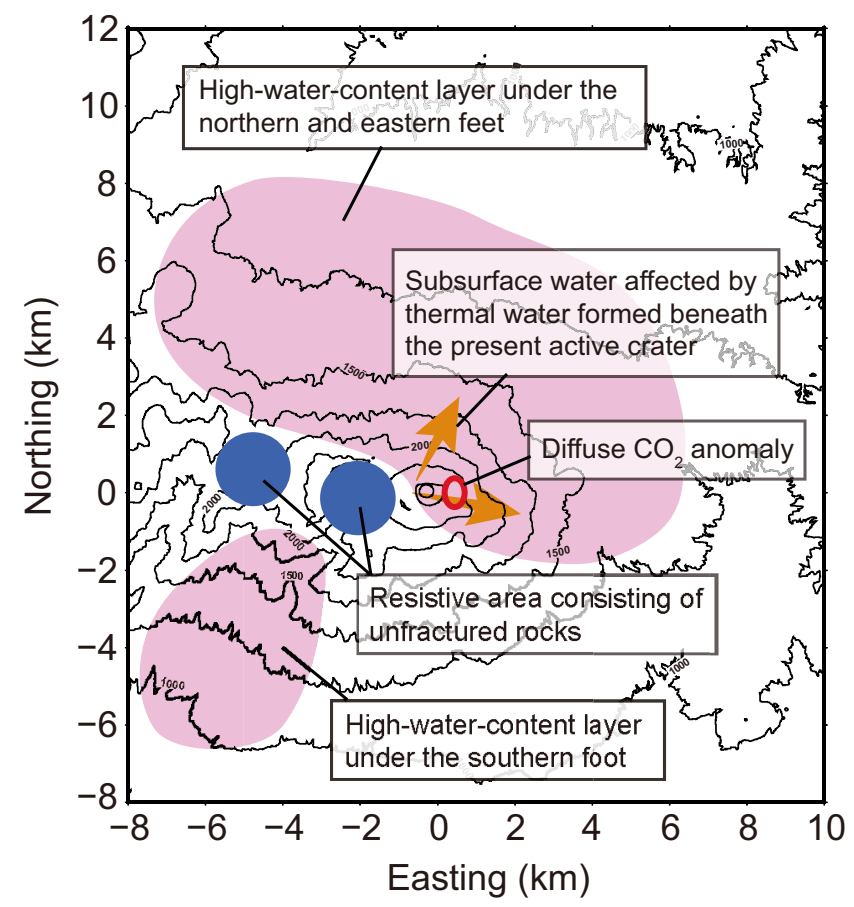

Figure 11. Schematic of the relation between the resistive area to the west of the present crater and subsurface fluids. The resistive area is inferred to contribute to the heterogeneity of the $\mathrm{SO}_{4}{ }^{2-}$ and $\mathrm{Cl}^{-}$concentrations of the spring water and the diffuse $\mathrm{CO}_{2}$ flux around the summit area by preferentially directing the flow of subsurface fluids to the east of the summit.

sity) for kindly sending us a copy of his doctoral thesis. In addition, we would like to thank P. Wannamaker, an anonymous reviewer and the editor in charge (U. Weckmann) for their valuable comments that significantly improved the manuscript. This study was supported by the 7th National Project for Volcano Eruption Prediction. For this study, we have used the computer systems of the Earthquake and Volcano Information Center of the Earthquake Research Institute, the University of Tokyo. Some figures were produced with the aid of Generic Mapping Tools (GMT) software (Wessel \& Smith 1998).

\section{REFERENCES}

Aizawa, K., Ogawa, Y., Hashimoto, T., Koyama, T., Kanda, W., Yamaya, Y., Mishina, M. \& Kagiyama, T., 2008. Shallow resistivity structure of Asama volcano and its implications for magma ascent process in the 2004 eruption, J. Volc. Geotherm. Res., 173, 165-177.

Aizawa, K., Ogawa, Y. \& Ishido, T., 2009a. Groundwater flow and hydrothermal systems within volcanic edifices: delineation by electric self-potential and magnetotellurics, J. geophys. Res., 114(1), 1-12.

Aizawa, K., Ogawa, Y., Mishina, M., Takahashi, K., Nagaoka, S., Takagi, N., Sakanaka, S. \& Miura, T., 2009b. Structural controls on the 1998 volcanic unrest at Iwate volcano: relationship between a shallow, electrically resistive body and the possible ascent route of magmatic fluid, J. Volc. Geotherm. Res., 187(1-2), 131-139.

Aizawa, K. et al., 2014. Three-dimensional resistivity structure and magma plumbing system of the Kirishima Volcanoes as inferred from broadband magnetotelluric data, J. geophys. Res., 119, 198-215.

Amante, C. \& Eakins, B.W., 2009. 'ETOPO1 1 arc-minute global relief model: procedures, data sources and analysis'. NOAA Technical Memorandum NESDIS NGDC-24, 19 pp. Available at: http://www.ngdc.noaa.gov/mgg/global/global.html, last accessed 31 May 2015.

Anderson, E. et al., 2000. LAPACK User's Guide, 3rd edn, SIAM. 
Aoki, Y. et al., 2009. P-wave velocity structure beneath Asama Volcano, Japan, inferred from active source seismic experiment, J. Volc. Geotherm. Res., 187, 272-277.

Aoki, Y., Takeo, M., Ohminato, M., Nagaoka, Y. \& Nishida, K., 2013. Magma Pathway and Its Structural Controls of Asama Volcano, Japan, Geol. Soc. London, Spec. Publ., 380 pp.

Aramaki, S., 1963. Geology of Asama volcano, J. Fac. Sci. Univ. Tokyo, 14(2), 229-443.

Avdeeva, A., Moorkamp, M., Avdeev, D.B., Jegen, M. \& Miensopust, M.P., 2015. Three-dimensional inversion of magnetotelluric impedance tensor data and full distortion matrix, Geophys. J. Int., 202(1), 464-481.

Cheng, S.-W, Dey, T.K. \& Shewchuk, J.R., 2012. Delaunay Mesh Generation, CRC Press.

Farquharson, J., Heap, M.J., Varley, N.R., Baud, P. \& Reuschlé, T., 2015. Permeability and porosity relationships of edifice-forming andesites: a combined field and laboratory study, J. Volc. Geotherm. Res., 297, $52-68$.

Garcia-Yeguas, A., Ibanez, J.M., Koulakov, I., Jakovlev, A., Romero-Ruiz, M.C. \& Prudencio, J., 2014. Seismic tomography model reveals mantle magma sources of recent volcanic activity at El Hierro Island (Canary Islands, Spain), Geophys. J. Int., 199(3), 1739-1750.

Geospatial Information Authority of Japan, 2011. 'Fundamental geospatial data'. Available at: http://fgd.gsi.go.jp/download/, last accessed 7 June 2015 (in Japanese).

Golub, G.H. \& Van Loan, C.F., 2013. Matrix Computations, 4th edn, Johns Hopkins Univ. Press.

Kanda, W., Tanaka, Y., Utsugi, M., Takakura, S., Hashimoto, T. \& Inoue, H., 2008. A preparation zone for volcanic explosions beneath Naka-dake crater, Aso volcano, as inferred from magnetotelluric surveys, J. Volc. Geotherm. Res., 178(1), 32-45.

Kanda, W., Utsugi, M., Tanaka, Y., Hashimoto, T., Fujii, I., Hasenaka, T. \& Shigeno, N., 2010. A heating process of Kuchi-erabu-jima volcano, Japan, as inferred from geomagnetic field variations and electrical structure, $J$. Volc. Geotherm. Res., 189(1-2), 158-171.

Kazama, T., Okubo, S., Sugano, T., Matsumoto, S., Sun, W., Tanaka, Y. \& Koyama, E., 2015. Absolute gravity change associated with magma mass movement in the conduit of Asama Volcano (Central Japan), revealed by physical modeling of hydrological gravity disturbances, J. geophys. Res., 120(2), 1263-1287.

Kordy, M., Wannamaker, P., Maris, V., Cherkaev, E. \& Hill, G., $2016 a$. 3-D magnetotelluric inversion including topography using deformed hexahedral edge finite elements and direct solvers parallelized on SMP computers-Part I: Forward problem and parameter Jacobians, Geophys. J. Int., 204(1), 74-93.

Kordy, M., Wannamaker, P., Maris, V., Cherkaev, E. \& Hill, G., 2016 b. 3-dimensional magnetotelluric inversion including topography using deformed hexahedral edge finite elements and direct solvers parallelized on symmetric multiprocessor computers-Part II: Direct data-space inverse solution, Geophys. J. Int., 204(1), 94-110.

Matsuno, T., Chave, A.D., Jones, A.G., Muller, M.R. \& Evans, R.L., 2014. Robust magnetotelluric inversion, Geophys. J. Int., 196(3), 1365-1374.

Morita, M., Mori, T., Kazahaya, R. \& Tsuji, H., 2016. Diffuse carbon dioxide emissions from hidden subsurface structures at Asama volcano, Japan, Bull. Volcanol., 78(3), 17, doi:10.1007/s00445-016-1008-5.

Müller, A. \& Haak, V., 2004. 3-D modeling of the deep electrical conductivity of Merapi volcano (Central Java): integrating magnetotellurics, induction vectors and the effects of steep topography, J. Volc. Geotherm. Res., 138(3-4), 205-222.

Nagaoka, Y., Nishida, K., Aoki, Y., Takeo, M. \& Ohminato, T., 2012. Seismic imaging of magma chamber beneath an active volcano, Earth planet. Sci. Lett., 333-334, 1-8.
Nam, M.J., Kim, H.J., Song, Y., Lee, T.J., Son, J.S. \& Suh, J.H., 2007. 3D magnetotelluric modelling including surface topography, Geophys. Prospect., 55(2), 277-287.

Nishiki, K., Takahashi, K. \& Matsumoto, A., 2013. Spatial and temporal change of volcanic field in Asama-Eboshi volcanoes, central Japan, J. geol. Soc. Japan, 119(7), 474-487 (in Japanese with English abstract).

Nurhasan, Ogawa, Y., Ujihara, N., Tank, S.B., Honkura, Y., Onizawa, S., Mori, T. \& Makino, M., 2006. Two electrical conductors beneath KusatsuShirane volcano, Japan, imaged by audiomagnetotellurics, and their implications for the hydrothermal system, Earth Planets Space, 58(8), 10531059.

Ogawa, Y. \& Uchida, T., 1996. A two-dimensional magnetotelluric inversion assuming Gaussian static shift, Geophys. J. Int., 126, 69-76.

Ogawa, Y., Matsushima, N., Oshima, H., Takakura, S., Utsugi, M., Hirano, K., Igarashi, M. \& Doi, T., 1998. A resistivity cross section of Usu volcano, Hokkaido, Japan, by audiomagnetotelluric soundings, Earth Planets Space, 50(4), 339-346.

Patro, B.P.K., Brasse, H., Sarma, S.V.S. \& Harinarayana, T., 2005. Electrical structure of the crust below the Deccan Flood Basalts (India), inferred from magnetotelluric soundings, Geophys. J. Int., 163(3), 931943.

Si, H., 2007. 'TetGen: a quality tetrahedral mesh generator and 3D Delaunay triangulator'. Available at: http://tetgen.berlios.de, last accessed 22 February 2014.

Siripunvaraporn, W. \& Egbert, G., 2009. WSINV3DMT: vertical magnetic field transfer function inversion and parallel implementation, Phys. Earth planet. Inter., 173(3-4), 317-329.

Siripunvaraporn, W., Egbert, G., Lenbury, Y. \& Uyeshima, M., 2005. Threedimensional magnetotelluric inversion: data-space method, Phys. Earth planet. Inter, 150(1-3), 3-14.

Suzuki, H., 2002. Chemical evolution of spring water and groundwater flow system in Asama volcano, Central Japan, PhD thesis, University of Tsukuba, (A), p. 2991.

Takahashi, M., Otsuka, T., Hirakawa, T., Nagai, M., Yasui, M. \& Aramaki, S., 2013. Whole-rock major element chemistry for eruptive products of the Eboshi Volcano Group, Central Japan: summary of 222 analytical data, in Proceedings of The Institute of Natural Sciences, Nihon University, Vol. 48, pp. 111-140 (in Japanese with English abstract)

Takeo, M., Aoki, Y., Ohminato, T. \& Yamamoto, M., 2006. Magma supply path beneath Mt. Asama volcano, Japan, Geophys. Res. Lett., 33(15), $1-5$.

Uchida, T., 1993. Smooth 2-D inversion for magnetotelluric data based on statistical criterion ABIC, J. Geomag. Geoelectr., 45(1990), 841858.

Ussher, G., Harvey, C., Johnstone, R., Anderson, E. \& Zealand, N., 2000. Understanding the resistivities observed in geothermal systems, in Proceedings, World Geothermal Congress 2000, Kyushu-Tohoku, Japan, pp. 1915-1920.

Usui, Y., 2015. 3-D inversion of magnetotelluric data using unstructured tetrahedral elements: applicability to data affected by topography, Geophys. J. Int., 202(2), 828-849.

Wannamaker, P., Stodt, J.A. \& Rijot, L., 1986. Two-dimensional topographic responses in magnetotellurics modeled using finite elements, Geophysics, 51(11), 2131-2144.

Wessel, P. \& Smith, W.H.F., 1998. New, improved version of generic mapping tools released, EOS, Trans. Am. geophys. Un., 79(47), 579-579.

Yamaya, Y., Alanis, P.K.B., Takeuchi, A., Cordon, J.M., Jr., Mogi, T., Hashimoto, T., Sasai, Y. \& Nagao, T., 2013. A large hydrothermal reservoir beneath Taal Volcano (Philippines) revealed by magnetotelluric resistivity survey: 2D resistivity modeling, Bull. Volcanol., 75(729), doi:10.1007/s00445-013-0729-y. 